\title{
Towards a long-term global aerosol optical depth record: applying a consistent aerosol retrieval algorithm to MODIS and VIIRS-observed reflectance
}

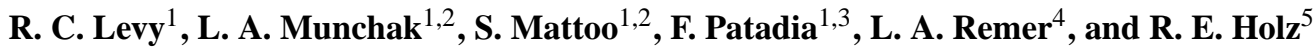 \\ ${ }^{1}$ NASA Goddard Space Flight Center, Greenbelt, MD, USA \\ ${ }^{2}$ SSAI, Lanham, MD, USA \\ ${ }^{3}$ GESTAR, Morgan State University, Columbia, MD, USA \\ ${ }^{4} \mathrm{UMBC} / \mathrm{JCET}$, Baltimore, MD, USA \\ ${ }^{5}$ SSEC, University of Wisconsin, Madison, WI, USA
}

Correspondence to: R. C. Levy (robert.c.levy@nasa.gov)

Received: 29 May 2015 - Published in Atmos. Meas. Tech. Discuss.: 8 July 2015

Revised: 11 September 2015 - Accepted: 16 September 2015 - Published: 7 October 2015

\begin{abstract}
To answer fundamental questions about aerosols in our changing climate, we must quantify both the current state of aerosols and how they are changing. Although NASA's Moderate Resolution Imaging Spectroradiometer (MODIS) sensors have provided quantitative information about global aerosol optical depth (AOD) for more than a decade, this period is still too short to create an aerosol climate data record (CDR). The Visible Infrared Imaging Radiometer Suite (VIIRS) was launched on the Suomi-NPP satellite in late 2011, with additional copies planned for future satellites. Can the MODIS aerosol data record be continued with VIIRS to create a consistent CDR? When compared to ground-based AERONET data, the VIIRS Environmental Data Record (V_EDR) has similar validation statistics as the MODIS Collection 6 (M_C6) product. However, the V_EDR and M_C6 are offset in regards to global AOD magnitudes, and tend to provide different maps of $0.55 \mu \mathrm{m}$ AOD and 0.55/0.86 $\mu \mathrm{m}$-based Ångström Exponent (AE). One reason is that the retrieval algorithms are different. Using the Intermediate File Format (IFF) for both MODIS and VIIRS data, we have tested whether we can apply a single MODISlike (ML) dark-target algorithm on both sensors that leads to product convergence. Except for catering the radiative transfer and aerosol lookup tables to each sensor's specific wavelength bands, the ML algorithm is the same for both. We run the ML algorithm on both sensors between March 2012 and May 2014, and compare monthly mean AOD time series with each other and with M_C6 and V_EDR products.
\end{abstract}

Focusing on the March-April-May (MAM) 2013 period, we compared additional statistics that include global and gridded $1^{\circ} \times 1^{\circ}$ AOD and AE, histograms, sampling frequencies, and collocations with ground-based AERONET. Over land, use of the ML algorithm clearly reduces the differences between the MODIS and VIIRS-based AOD. However, although global offsets are near zero, some regional biases remain, especially in cloud fields and over brighter surface targets. Over ocean, use of the ML algorithm actually increases the offset between VIIRS and MODIS-based AOD (to $\sim 0.025$ ), while reducing the differences between AE. We characterize algorithm retrievability through statistics of retrieval fraction. In spite of differences between retrieved AOD magnitudes, the ML algorithm will lead to similar decisions about "whether to retrieve" on each sensor. Finally, we discuss how issues of calibration, as well as instrument spatial resolution may be contributing to the statistics and the ability to create a consistent MODIS $\rightarrow$ VIIRS aerosol CDR.

\section{Introduction}

Aerosols are important components of the climate system, and to answer fundamental questions about our changing climate, we must quantify the role of aerosols and how those aerosols are changing over time. The magnitude of aerosol forcing is difficult to assess because their loading and prop- 
erties vary in space and time due to intermittency of some sources (e.g., fires, volcanoes and wind-driven dust), variable weather that affect transport and sinks, and secular trends caused by human policy. While the Intergovernmental Panel on Climate Change (IPCC, 2013) has recently reported reduced uncertainty as to aerosol loadings and aerosol radiative forcing effects on a global scale, it is also clear that changes in aerosol are regional.

Whether aerosol loadings are increasing or decreasing depends on location. For example, aerosols have decreased dramatically over eastern Europe and increased over India and China (Chin et al., 2013). Regional aerosol changes (Zhang and Reid, 2010) affect regional weather and local air quality, with regional effects having global consequences, including health (e.g., van Donkelaar et al., 2010) and economic consequences (Lin et al., 2014). Therefore, it is imperative that the community has a consistent, long-term aerosol data set, which is global in construct, but with resolution and accuracy sufficient to resolving regional trends.

To this end, the European Space Agency (ESA), through their Climate Change Initiative (CCI) has recently identified some Essential Climate Variables (ECVs) to monitor (e.g., Hollmann et al., 2013). One ECV is aerosol optical depth (AOD), and the World Meteorological Organization has set some "targets" for its measurement characteristics (GCOS, 2011). Specifically, for an AOD data set to be considered a climate data record (CDR; e.g., NRC, 2004), it should be able to be measured globally, every $4 \mathrm{~h}$, at a resolution of 5$10 \mathrm{~km}$, with accuracy of $\pm(0.03+10 \%)$ and stability of 0.01 per decade. A data record of at least 30 years is a suggested minimum for assessing global change.

The satellite aerosol record does span more than 3 decades, if retrievals from the Advanced Very High Resolution Radiometer (AVHRR) and Total Ozone Measurements (TOMS) are considered. Yet, these instruments are limited in their spectral and spatial information content, and also by their lack of consistent sampling (due to changes in orbit) and calibration. Attempts to stitch AVHRR and TOMS time series into more modern aerosol records (Mishchenko et al., 2007a; Chan et al., 2013; Zhao et al., 2013) have helped to derive global trends (e.g., Torres et al., 2002; Mishchenko et al., 2007b, 2012), but their large differences in sampling and retrieval capability make it difficult to determine regional trends. Because the long-term aerosol variability is small (global trends of $<0.01$ decade; e.g., Hsu et al., 2012) and usually embedded in the much larger variability associated with the shorter (such as seasonal) time scale, we require not only a long-term data set, but also one that is consistent across instrument sampling, calibration and retrieval algorithms (e.g., Weatherhead et al., 1998).

NASA's space-borne Earth Observing System (EOS) sensors have been observing the Earth system (land, oceans and atmosphere) for over 15 years. While not meeting requirements of 4 times daily observation, the EOS system observes aerosol over nearly the entire globe, with spatial and temporal resolution sufficient to study the regional and local scales. One of the primary instruments of EOS is the Moderate Resolution Imaging Spectroradiometer (MODIS; Salomonson et al., 1989), which has been flying on Terra since December 1999 and on Aqua since May 2002. From MODIS-observed reflectance in the visible (VIS), nearinfrared (NIR) and shortwave-IR (SWIR) wavelength regions, the so-called "dark-target" (DT) aerosol algorithm (e.g., Levy et al., 2007a, b, 2010, 2013; Remer et al., 2005, 2008) has been retrieving total aerosol optical depth (AOD) at $0.55 \mu \mathrm{m}$ over land and ocean at nominal $10 \times 10 \mathrm{~km}$ spatial resolution. These MODIS aerosol products are being used for all sorts of applications, both research and routine, and recently, upgraded retrieval capability has been applied to produce the Collection 6 (C6; http://modis-atmos.gsfc.nasa.gov) time series. For a small subset of C6 DT products, Levy et al. (2013) compared retrieved AOD to ground and shipbased Aerosol Robotic Network (AERONET) sunphotometer data (Holben et al., 1998; Smirnov et al., 2009), and determined global, one-sigma expected error (EE) envelopes to be approximately $(0.04+10 \% ;-0.02-10 \%)$ over ocean and $\pm(0.05+15 \%)$ over land. This performance comes close to the requirements as stated in the WMO document (GCOS, 2011).

Although the MODIS DT retrieval algorithm is mature and well characterized, both MODIS instruments have exceeded their designed lifetime. In 2006, Remer et al. (2008) showed that Terra-MODIS and Aqua-MODIS retrieved nearly identical aerosol statistics over the ocean. Two years later, Remer et al. (2008) found that Terra had acquired a $0.015(12 \%)$ offset from Aqua. Over land, the offset was changing with time, suggestive of calibration drift for Terra (e.g., Levy et al., 2010). Although steps were taken by the MODIS Calibration and Support Team (MCST) to reduce the drifting for C6, it is expected (e.g., Levy et al., 2013) that the TerraAqua offset $(\sim 0.015)$ will remain for C6. However, Lyapustin et al. (2014), showed how that with even greater attention to recalibration and normalization, it may be possible to homogenize the Terra-Aqua aerosol records.

Regardless of continued re-calibration and reprocessing of the MODIS data, MODIS will be decommissioned by the early 2020s; there will never be a 30 year AOD record from MODIS. However, with the launch of the Visible Infrared Imaging Radiometer Suite (VIIRS) instrument onboard Suomi-NPP (S-NPP) in late 2011, there is hope that VIIRS can continue the MODIS aerosol record into the Joint Polar Satellite System (JPSS) era. VIIRS was designed to have similar capabilities as MODIS, with similar visible/NIR/IR spectral channels, similar spatial and temporal resolution, and similar physics behind the retrieval algorithms. In fact, NOAA (through the Interface Data Processing Segment, IDPS) is already delivering an AOD product (Jackson et al., 2013) that is meeting expected accuracies, which means performing to within similar EE envelopes stated for the MODIS product (Liu et al., 2014). Although the VIIRS- 
IDPS is providing a quality aerosol product especially over ocean, the creation of a long-term AOD record not only requires the availability of data, but also that the time series has no gaps or jumps (Hollman et al., 2013).

Since any potential trend in AOD is likely to be less than $10 \%$ per decade, and global AOD is on order of $\sim 0.2$, a climate data record needs to be able to characterize AOD differences of $\sim 0.02$ or less. Using one satellite to detect this aerosol trend requires the ability to separate out background noise, characterize uncertainty in the retrieval and diagnose calibration drifts. While aggregation and averaging helps to beat down uncertainties related to noise and retrieval uncertainty, averaging cannot help a calibration drift.

CDR creation is difficult with one sensor, but becomes even more difficult when using two. The recent experience with twin MODIS instruments with the same retrieval algorithms, but on different platforms, highlights how calibration may confound the issue (e.g., Lyapustin et al., 2014). Likewise, two instruments on the same platform (e.g., the Multi-angle Imaging SpectroRadiometer (MISR) and MODIS which are both on Terra), do not agree within CDR specifications (e.g., Liu and Mishchenko, 2008). The differences in algorithms, sampling and pixel resolution lead to discrepancies in regional and global AOD and their trends. MODIS and VIIRS are different instruments on different platforms. Thus, it follows that even if the VIIRS-IDPS continues to provide a successful aerosol product, there are many obstacles to creating a merged aerosol climate data record from MODIS and VIIRS. These issues were discussed by Hsu et al. (2013a), to include the following.

- sensor differences,

- calibration/characterization differences,

- sampling (orbital coverage) differences,

- retrieval algorithm differences,

- pixel selection, including cloud and other masking,

- aggregation/averaging from along-orbit products (e.g., Level 2), to gridded, global products (e.g., Level 3).

We cannot control the sensor differences, calibration or how the different platforms orbit around the globe. However, we can test whether we can homogenize the retrieval algorithm, pixel selection and aggregation strategies, and thus reduce the differences between MODIS and VIIRS. We will briefly describe the current MODIS and VIIRS-IDPS algorithms in Sect. 2, and show that the current VIIRS-IDPS aerosol product is significantly different from the MODIS data set for overlapping scenes and statistics. In Sect. 3, we develop a MODIS-like (ML) algorithm to apply to VIIRS spectral observations. In Sect. 4, we compare statistics of our MODIS-like data to the M_C6 and VIIRS-IDPS products, and also to ground-based sunphotometer measurements. A first attempt at overlapping time series is shown in Sect. 5. In Sect. 6, we hypothesize why complete convergence may be difficult, along with further avenues to study. Section 7 concludes that there is nothing inherent in the VIIRS sensor itself to prevent the creation of a long-term CDR with a consistent algorithm to both sensors, but that a reliable MODIS $\rightarrow$ VIIRS CDR will take much more work.

\section{Comparison of MODIS-C6 and VIIRS-IDPS: algorithm, sensor and products}

\subsection{Theoretical perspective}

Kaufman et al. (1997a) explains how the clear-sky, top-ofatmosphere (TOA) radiance, observed by a passive satellite, is a combination of contributions from two sources: the atmospheric path radiance (including aerosol and Rayleigh scatterings) and the contribution from the Earth's surface (including coupling between the surface and atmosphere). Retrieval of aerosol properties from this complicated TOA signal, therefore, requires knowledge about the surface optical properties and non-aerosol contributions. It also requires reasonable constraints on the aerosol optical properties. To a first approximation, the spectral reflectance at the TOA is

$\rho^{*}=\rho^{\mathrm{a}}+\left(T^{\uparrow} T^{\downarrow} \rho^{\mathrm{s}}\right) /\left(1-\left[\bar{s} \rho^{\mathrm{s}}\right]\right)$,

where $\rho^{*}$ is the reflectance at the TOA, $\rho^{\mathrm{a}}$ is the reflectance of the atmosphere (also known as the path radiance), $\rho^{\mathrm{s}}$ is the surface reflectance, $\bar{s}$ is the upscattering ratio, and $T^{\uparrow}$ and $T \downarrow$ are the atmospheric transmissions (up and down) of the surface reflectance. Except for $\bar{s}$, all of these terms have angular and wavelength dependence. Except for the surface reflectance, all terms depend on the aerosol type and column loading. The path radiance term also includes contributions from Rayleigh (molecular) scattering.

Equation (1) is the basis of aerosol remote sensing for MODIS, but there are many different approaches to applying this equation. Although there are many additional algorithms, Table 1 lists three of the aerosol algorithms developed and now currently used for retrieval aerosol properties from MODIS.

The first two of these algorithms we denote as darktarget (DT) algorithms, which are separated into over ocean (DT_O; Tanré et al., 1997; Remer et al., 2005; Levy et al., 2013) and over land (DT_L; Kaufman et al., 1997a; Remer et al., 2005; Levy et al., 2007a, b, 2013). Both are explicit aerosol retrieval algorithms that result in aerosol products that are packaged and presented as parameters within standard Terra (MOD04) or Aqua (MYD04) aerosol product files (collectively denoted as MxD04). These algorithms are "dark-target" because they are used for scenes where Earth's surface has low reflectance (is dark) in selected VIS, NIR and SWIR wavelengths. These wavelengths are also in window regions of the atmosphere (have small gas absorption). Since the surface reflectance is relatively small, the aerosol 
Table 1. Three MODIS products and their references.

\begin{tabular}{|c|c|c|c|c|}
\hline Index & $\begin{array}{l}\text { MODIS } \\
\text { procedure }\end{array}$ & $\begin{array}{l}\text { Geophysical } \\
\text { parameters }\end{array}$ & $\begin{array}{l}\text { MODIS L2 } \\
\text { product name }\end{array}$ & References \\
\hline DT_O & $\begin{array}{l}\text { Dark-target aerosol } \\
\text { over ocean }\end{array}$ & $\mathrm{AOD}$, fine fraction & MxD04 & $\begin{array}{l}\text { Tanré et al. (1997); } \\
\text { Remer et al. (2005) }\end{array}$ \\
\hline DT_L & $\begin{array}{l}\text { Dark-target aerosol } \\
\text { over land }\end{array}$ & AOD & MxD04 & $\begin{array}{l}\text { Kaufman et al. (1997); } \\
\text { Remer et al. (2005); } \\
\text { Levy et al. }(2007 a, b)\end{array}$ \\
\hline AC_L & $\begin{array}{l}\text { Atmospheric } \\
\text { correction over land }\end{array}$ & Surface reflectance & MxD09 & $\begin{array}{l}\text { Vermote et al. (1997); } \\
\text { Vermote and Kotchenova (2008) }\end{array}$ \\
\hline
\end{tabular}

signal is a major component of the TOA signal. The portion of the TOA signal attributed to aerosol can be estimated with radiative transfer, and using lookup tables (LUTs), one can retrieve the properties of the aerosol (AOD and aerosol type or model) that contributed to this aerosol portion. In this process, by iterating through increasing values of AOD and various candidate aerosol models, the algorithm finds an optimal solution that best matches the reflectance measurements to the theoretical (LUT) values at the TOA.

The DT algorithm constrains the surface (either implicitly or explicitly). With DT_O, the surface contribution is modeled explicitly (Ahmad and Fraser, 1982) as an addition of a flat dark ocean (nearly black in NIR and SWIR channels), plus some water leaving radiance (in VIS channels), plus whitecaps, foam and glitter (e.g., Cox and Munk, 1954; Koepke, 1984). Over land, although the land surface reflectance varies greatly with season and location, Kaufman et al. (1997b) found that, over vegetation and dark soils, the surface reflectance in a blue wavelength is approximately equal to half that in a red wavelength, which is in turn half that of a SWIR wavelength (e.g., near $2.1 \mu \mathrm{m}$ ). This land surface parameterization is applied to the DT_L to constrain systems of equations (one for each wavelength). For both DT algorithms, the goodness of fit is judged by the closeness between computed and measured TOA reflectance in the selected channels.

The third algorithm (AC_L; Vermote et al., 1997, 2002) listed in Table 1 derives aerosol information internally and uses the aerosol information for deriving atmospherically corrected surface products (the "MxD09" product). The AC_L algorithm used for MxD09 shares a common developer heritage with the DT_L used for MxD04 (note overlap of authors between Kaufman et al., 1997a and Vermote et al., 1997). However, instead of solving for the TOA reflectance $\rho^{*}$ as the DT algorithm, it inverts the equation and solves for the surface reflectance, $\rho^{\mathrm{s}}$. The comparison between the derived and expected spectral surface reflectance determines the best solution. Since 1997, the AC_L and DT_L algorithms and products have diverged because of different needs. DT_L tries to derive aerosol properties (Remer et al., 2005; Levy et al., 2007a, b), regardless of surface con- ditions, and AC_L tries to derive land properties regardless of atmosphere conditions (Vermote and Kotchenova, 2008). DT_L must retrieve aerosol at all aerosol loadings, including very heavy aerosol events, while AC_L can choose to ignore these heavy events to ensure accurate surface retrievals. Theoretically, the resulting AOD and aerosol model could be similar to that of a DT algorithm, but in practice, this may not be the case.

\subsection{A short history}

The MODIS DT algorithm has been updated since formulation in the 1990s and implementation on Terra and Aqua. In MODIS terminology, a stable combination of algorithm version and product version is known as a Collection, which we refer to by $\mathrm{C} X$ where $X$ is a number. $\mathrm{C} 2$ began at launch, $\mathrm{C} 3$ began soon after, and $\mathrm{C} 4$ denoted the first attempt to combine forward processing and reprocessing of old data. By late 2005 the DT_L and DT_O aerosol retrieval algorithms became stable. The $\mathrm{C} 5$ aerosol data set (MxD04) was processed with identical DT aerosol retrieval algorithms on both Terra and Aqua, theoretically leading to a consistent MODIS aerosol data record. However, as explained in the introduction, using a common algorithm for the entire data mission did not ensure a CDR-quality data set. Differences in calibration crept in, leading to artificial trending of AOD. Starting in 2014, the entire MODIS mission is being processed again with updated algorithms. Corrections to calibration have been applied, and the products are known as Collection 6 (C6; Levy et al., 2013). The MODIS C6 (M_C6) data cover the entirety of the MODIS mission, including temporal overlap with VIIRS.

Development for the VIIRS algorithms over land and ocean (V_L and V_O) began in the early 2000s, concurrent with earlier versions of the MODIS algorithms. At this point the personnel overlap between algorithm teams disappeared, causing the algorithms to diverge. The V_L algorithm is a variant of the AC_L algorithm, which employs extra blue wavelengths that help constrain aerosol type (Vermote and Kotchenova, 2008). The V_O algorithm is directly adapted from DT_O, but with adjustments and modifications. For example, the spectral inversion for V_O does not use a green 
Table 2. MODIS and VIIRS instrument specifications.

\begin{tabular}{lll}
\hline & Aqua-MODIS & Suomi NPP-VIIRS \\
\hline Orbit altitude & $705 \mathrm{~km}$ & $824 \mathrm{~km}$ \\
Equator crossing time & $13: 30 \mathrm{LT}$ & $13: 30 \mathrm{LT}$ \\
Swath width & $2330 \mathrm{~km}$ & $3040 \mathrm{~km}$ \\
Sensor zenith angle range & $\pm 64^{\circ}$ & $\pm 70^{\circ}$ \\
Wavelength bands & $36 \mathrm{bands}(20$ in solar spectrum $)$ & 22 bands $(15$ in solar spectrum $)$ \\
Pixel size, nadir & $1.0 / 0.50 / 0.25 \mathrm{~km}$ & $0.75 / 0.375 \mathrm{~km}$ \\
Pixel growth factor, edge of scan & $4.8 \times 2.0$ & $1.6 \times 1.6$ \\
Bow-tie effects & Yes & Decreased \\
\hline
\end{tabular}
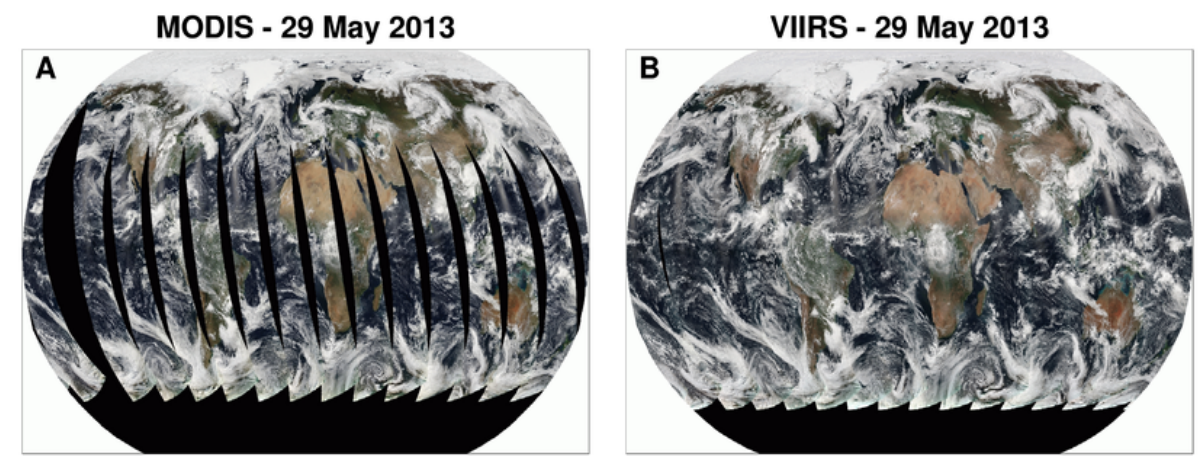

Figure 1. "True-color" RGB images for MODIS (a) and VIIRS (b), created from all orbits during 29 May 2013. Note the increased VIIRS swath width, and full daily global coverage.

$(0.55 \mu \mathrm{m})$ channel like DT_O, but uses $0.75 \mu \mathrm{m}$ channel instead. Unlike the MODIS-DT algorithm, where ocean properties are included in the LUT, the VIIRS algorithm analytically computes the ocean surface properties, and then couples with an atmosphere-only LUT. For both land and ocean, the VIIRS algorithms use different radiative transfer codes for LUTs, as well as different formulas for determining goodness of fit between LUTs and observations (Hsu et al., 2013a; Jackson et al., 2013).

As described by Jackson et al. (2013), the current IDPS algorithms have undergone numerous changes since the "atlaunch" algorithm. For example, the assumed blue/red to SWIR surface relationship for V_L was updated once sufficient statistics were accumulated to provide a better empirical relationship than the pre-launch proxy data allowed (e.g., Liu et al., 2014). The latest versions have been applied to VIIRS since February 2013. The IDPS algorithm continues to evolve quickly, and will likely undergo a series of updates during its first 5 years of post-launch operation. The version analyzed in this work is referred to as "validated stage 2" in the IDPS nomenclature. We denote the time series of operational VIIRS-IDPS data as the VIIRS Environmental Data Record (V_EDR).

\subsection{Sensor differences}

Table 2 shows that although the MODIS (on Aqua) and VIIRS sensors are mostly similar, there are also some key differences. VIIRS on S-NPP orbits at $824 \mathrm{~km}$, compared to MODIS aboard Aqua orbiting from $705 \mathrm{~km}$, and has a larger sensor view zenith angle $\left( \pm 70^{\circ}\right.$ compared to $\pm 64^{\circ}$ for MODIS), which both allow VIIRS to have a significantly larger ground swath than MODIS $(3040 \mathrm{~km}$ compared to $2330 \mathrm{~km}$ for MODIS). Although VIIRS and MODIS-Aqua both have similar local equator crossing times (1.30 p.m.), they overlap exactly (viewing a target from nadir and at the same time) only every 3 days and only over polar sites (Uprety et al., 2013). Over a given mid-latitude or tropical site, MODIS and VIIRS observe with varying offsets, ranging from a few minutes apart (with similar solar/viewing geometry) on some days, to multiple hours apart (with different geometry) on others. In Fig. 1 we plot 1 day's (29 May 2013) orbits worth of both MODIS and VIIRS imagery, showing coverage differences between the two orbits.

MODIS has 36 wavelength bands, of which 20 are in the solar spectrum $(\lambda<3.8 \mu \mathrm{m})$. Depending on band, MODIS pixels are either $0.25 \mathrm{~km} \times 0.25 \mathrm{~km}$ ( 2 bands), $0.5 \mathrm{~km} \times 0.5 \mathrm{~km}$ ( 5 bands) or $1 \mathrm{~km} \times 1 \mathrm{~km}$ (the remainder) at nadir. VIIRS has 22 bands of which 15 are in the solar spectrum. Three are high-resolution "imagery" bands (I-bands) at $0.375 \mathrm{~km}$ and the rest are at moderate $(0.75 \mathrm{~km})$ resolution at nadir $(\mathrm{M}$ - 
Table 3. MODIS and VIIRS spectral configuration and aerosol algorithm use of channels.

\begin{tabular}{|c|c|c|c|}
\hline $\begin{array}{l}\text { MODIS band } \\
(\mu \mathrm{m}) \text { and native } \\
\text { resolution }\end{array}$ & $\begin{array}{l}\text { How used within } \\
\text { MODIS DT } \\
\text { algorithm }\end{array}$ & $\begin{array}{l}\text { VIIRS band }(\mu \mathrm{m}) \\
\text { and native } \\
\text { resolution }\end{array}$ & $\begin{array}{l}\text { How used within } \\
\text { VIIRS-IDPS } \\
\text { aerosol algorithm }\end{array}$ \\
\hline B8: $0.41(1 \mathrm{~km})$ & & M1: $0.41(0.75 \mathrm{~km})$ & V_L \\
\hline B9: $0.44(1 \mathrm{~km})$ & & M2: $0.44(0.75 \mathrm{~km})$ & V_L \\
\hline B3: $0.47(0.5 \mathrm{~km})$ & DT_L & & \\
\hline B10: $0.49(1 \mathrm{~km})$ & & M3: $0.49(0.75 \mathrm{~km})$ & V_L \\
\hline \multicolumn{4}{|l|}{ B11: $0.53(1 \mathrm{~km})$} \\
\hline \multicolumn{4}{|l|}{ B12: $0.55(1 \mathrm{~km})$} \\
\hline B4: $0.55(0.5 \mathrm{~km})$ & DT_O & $\begin{array}{l}\text { M4: } 0.55(0.75 \mathrm{~km}) \\
\text { I1: } 0.64(0.375 \mathrm{~km})\end{array}$ & \\
\hline B1: $0.65(0.25 \mathrm{~km})$ & DT_L, DT_O & & \\
\hline $\begin{array}{l}\text { B13: } 0.67(1 \mathrm{~km}) \\
\text { B14: } 0.68(1 \mathrm{~km})\end{array}$ & & M5: $0.67(0.75 \mathrm{~km})$ & V_L, V_O \\
\hline B15: $0.75(1 \mathrm{~km})$ & & M6: $0.75(0.75 \mathrm{~km})$ & V_O \\
\hline B2: $0.86(0.25 \mathrm{~km})$ & DT_L, DT_O & M7: $0.86(0.75 \mathrm{~km})$ & V_L, V_O \\
\hline B16: $0.87(1 \mathrm{~km})$ & & $\mathrm{I} 2: 0.86(0.375 \mathrm{~km})$ & \\
\hline \multicolumn{4}{|l|}{ B17: $0.90(1 \mathrm{~km})$} \\
\hline \multicolumn{4}{|l|}{ B18: $0.94(1 \mathrm{~km})$} \\
\hline \multicolumn{4}{|l|}{ B19: 0.94 (1 km) } \\
\hline \multirow[t]{2}{*}{ B5: $1.24(0.5 \mathrm{~km})$} & DT_L, DT_O & M8: $1.24(0.75 \mathrm{~km})$ & V_O and Snow/Ice/ \\
\hline & $\begin{array}{l}\text { Snow/Ice/Sediment/ } \\
\text { Cirrus mask }\end{array}$ & & $\begin{array}{l}\text { Sediment/Cirrus } \\
\text { mask }\end{array}$ \\
\hline \multirow[t]{3}{*}{ B26: $1.38(1 \mathrm{~km})$} & Cirrus mask & M9: $1.38(0.75 \mathrm{~km})$ & Cirrus mask \\
\hline & & I3: $1.60(0.375 \mathrm{~km})$ & \\
\hline & & M10: $1.60(0.75 \mathrm{~km})$ & V_O \\
\hline B6: $1.63(0.5 \mathrm{~km})$ & DT_O & & \\
\hline \multirow[t]{2}{*}{ B7: $2.11(0.5 \mathrm{~km})$} & DT_L, DT_O & & \\
\hline & & M11: $2.26(0.75 \mathrm{~km})$ & $\begin{array}{l}\text { V_L, V_O, } \\
\text { bright surface mask }\end{array}$ \\
\hline
\end{tabular}

bands). For MODIS, the higher-resolution bands are also aggregated and reported at lower resolution, whereas for VIIRS the M-bands and I-bands are observed independently. For both MODIS and VIIRS, the higher spatial resolution bands have a wider spectral width than the lower resolution bands, which increases signal to noise, but also means that they may extend into gas absorption regions. The spatial resolution of pixels becomes coarser away from nadir towards the edges of the scan. This results in issues of oversampling, as well as bow-tie distortion (http://eoweb.dlr.de:8080/short_guide/ D-MODIS.html) near swath edge. For MODIS, the pixel size grows four-fold so that a $0.5 \mathrm{~km} \times 0.5 \mathrm{~km}$ pixel at nadir becomes roughly $2.5 \mathrm{~km} \times 1 \mathrm{~km}$ at swath edge. VIIRS is designed to mitigate the pixel stretching and distortion in two ways. Despite VIIRS's wider swath, the M-band resolution at swath edge has only doubled in size from 0.75 to $1.2 \mathrm{~km}$. VIIRS data also have a pixel deletion algorithm, which reduces over sampling.

As described in Sect. 2.1, the MODIS DT and VIIRSIDPS algorithms have been developed separately and optimized for application on their respective sensors. Table 3 shows which VIS, NIR and SWIR band configurations for
MODIS and VIIRS, as well as which bands are used for the MODIS-DT (DT_L and DT_O) and VIIRS-IDPS (V_L and V_O) algorithms. If there is direct "overlap" within the bands (e.g., band centers are within $\pm 0.01 \mu \mathrm{m}$ ), they are in the same row. For example, $0.86 \mu \mathrm{m}$ is used on both sensors for aerosol retrieval (M7 vs. B2). On the other hand, there are bands used for MODIS DT with no direct counterpart for VIIRS aerosol retrieval, and vice-versa. For example, while there is a $0.55 \mu \mathrm{m}$ band on VIIRS, it is not used for aerosol retrieval. There is no VIIRS band that corresponds directly to MODIS B1, B3 or B7, but nearby bands (e.g., $\pm 0.03 \mu \mathrm{m}$ ) are used. Band centers are calculated from online data for relative spectral response (RSR).

We note that while a listed band may not be used within the DT or VIIRS aerosol retrieval algorithms, it may be used by an alternative aerosol retrieval (e.g., Hsu et al., 2013b) or retrieval of other geophysical products (e.g., ocean color). Additional bands (not listed, e.g., the IR bands) are used for routine cloud masking or other tests. 


\subsection{Practical differences}

The MODIS DT and VIIRS-IDPS aerosol retrieval teams have adopted different strategies for increasing the robustness of their retrieved products. This includes steps to mask pixels that are unsuitable for aerosol retrieval (e.g., clouds, glint, etc.) as well as steps to assess confidence in the final product.

To identify and mask clouds, the MODIS DT algorithm combines internal spatial variability and reflectance threshold tests with three thermal IR tests from the external Wisconsin cloud mask (MxD35, e.g., Frey et al., 2008). The VIIRS-IDPS algorithm relies on an upstream VIIRS Cloud Mask (VCM; e.g., Vermote et al., 2014; Kopp et al., 2014) for cloud masking. Both algorithms have their own methods for screening out snow, ice, glint, and other pixels unsuitable for retrieval.

Even after unambiguously unsuitable pixels are discarded, pixel by pixel retrieval can create a noisy product (e.g., Tanré et al., 1997). To increase signal and robustness in the product, one could either aggregate the pixels (then do one aerosol retrieval), or do pixel retrievals but then average the results. The strategy for the MODIS DT algorithm is the former, which means it creates $20 \times 20$ boxes of nominal $0.5 \mathrm{~km}$ data, and derives an "average" spectral reflectance that represents the nominal $10 \mathrm{~km}$ box. When creating this average, the masked pixels are discarded, along with some fraction of the remainder, in order to ensure that the retrieval is based on appropriate pixels. The retrieval is made once for a $10 \mathrm{~km}$ box. On the other hand, the VIIRS-IDPS strategy is to retrieve on every $0.75 \mathrm{~km}$ pixel that is not masked (e.g., clouds), known as the intermediate product (IP). To create a final product (at $6 \mathrm{~km}$ resolution), the algorithm aggregates an $8 \times 8$ box of these $0.75 \mathrm{~km}$ pixels. Although the end result for both the MODIS-DT and VIIRS-IDPS algorithms is a robust retrieval of aerosol properties, the strategies for attaining it differ.

On MODIS, the DT algorithms' primary products are total aerosol optical depth (AOD at $0.55 \mu \mathrm{m}$ ) over land and ocean, plus information about particle size over ocean. This size information is reported in a number of ways including: fraction of AOD (at $0.55 \mu \mathrm{m}$ ) contributed by small particles known as fine mode fraction or FMF; the Ångström exponents (AE) for two wavelength pairs $(0.55 / 0.86$ and $0.86 / 2.11 \mu \mathrm{m})$; the effective radius; and spectral AOD at seven wavelengths. All other MODIS DT products are either derived from these primary products or are diagnostics of the retrieval. Note that prior to C6, MODIS also included AE over land $(0.47 / 0.65 \mu \mathrm{m})$ but was dropped from the product list due to having little quantitative value (e.g., Levy et al., 2013).

VIIRS produces the same basic information as MODIS: AOD at $0.55 \mu \mathrm{m}$ over land and ocean, plus a particle size parameter over ocean. However, the VIIRS size parameter over ocean is given only as an $\mathrm{AE}$ for the wavelength pair $0.86 / 1.61 \mu \mathrm{m}$ and as spectral AOD in 11 wavelengths. There is no effective radius product, and FMF is a diagnostic only available at the IP level. VIIRS produces an AE over land $(0.49 / 0.67 \mu \mathrm{m})$, but preliminary validation suggests there is no quantitative skill. We will not further discuss AE over land.

Jackson et al. (2013) and Liu et al. (2014) discuss the concepts of quality assurance (QA) as applied to the VIIRSIDPS algorithm, while Levy et al. (2013) discusses QA in relation to the MODIS DT algorithm for C6. The criteria and definitions differ, but the end result is an integer that ranges from 0 to 3 , roughly representing the range of "no confidence" to "high confidence" in the retrieved product.

\subsection{Product differences}

Although the VIIRS retrieval algorithm was developed independently, the primary product of both the MODIS DT and VIIRS-IDPS algorithms is the AOD at $0.55 \mu \mathrm{m}$. Liu et al. (2014) have already performed comparison of MODIS C5 and VIIRS-IDPS data, but since then, the MODIS algorithm has been updated to C6. Therefore, we start with comparisons of MODIS C6 (M_C6) and VIIRS-IDPS data (the V_EDR) products after 23 February 2013.

Figure 2 presents red-green-blue (RGB) imagery and AOD retrieval for a near-overlapping scene over India and the Bay of Bengal. Both MODIS and VIIRS images start at 07:35 UTC on 5 March 2013, but with ground-track separated by about $350 \mathrm{~km}$. 3.5 VIIRS $86 \mathrm{~s}$ granules were stitched together to resemble one MODIS $5 \mathrm{~min}$ granule. The MODIS AOD is plotted with $10 \mathrm{~km}$ resolution (at nadir), meeting the quality assurance confidence (QAC) requirements for MODIS (QAC $\geq 1$ over-ocean and $\mathrm{QAC}=3$ over land). The VIIRS AOD is plotted for $6 \mathrm{~km}$ pixels with the VIIRS team's $\mathrm{QAC}$ recommendations ( $\mathrm{QAC}=3$ for both ocean and land). Although the surface issues and cloud patterns appear the same for the common sampling, the retrieved AOD values are different, especially over land. Over Bangladesh, MODIS retrieves much higher AOD $(\sim 0.7)$ than VIIRS $(\sim 0.4)$. Over much of India, MODIS retrieves near zero values, with VIIRS not retrieving at all. Clearly, there are differences in where each sensor chose to retrieve, whether due to suspicion of clouds or surface issue. On the other hand, where not impacted by glint, the coverages and magnitudes over ocean are very similar, including both showing the tiny plume off to the west of the Malay Peninsula.

Seasonally averaged AOD maps for March-April-May (MAM) 2013 are shown in Fig. 3, following the aggregation strategy described in Levy et al. (2013) for calculating monthly mean. For sufficient QAC, at least five pixels are required to create a daily mean for a given $1^{\circ} \times 1^{\circ}$ grid, and at least 3 days are required to create a seasonal mean. While 3 days may not be sufficiently representative of a seasonal mean, we assume it is for comparison purposes. Figure 4 presents scatterplots for (V_EDR vs. M_C6) of the seasonal 
MODIS RGB

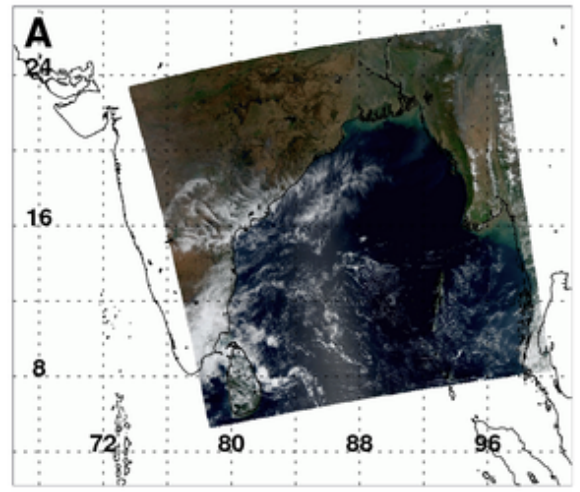

MODIS C6 AOD

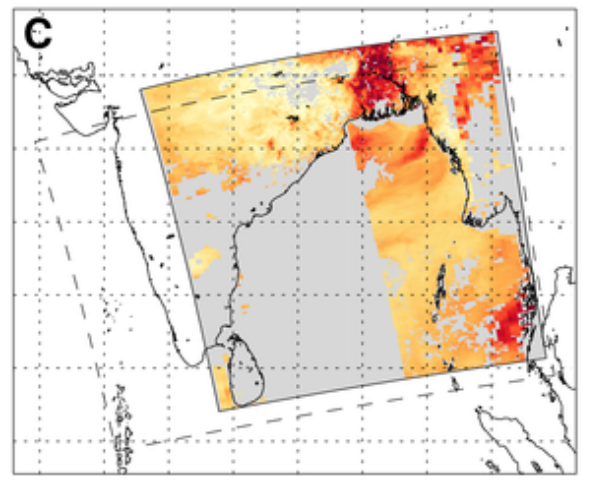

$0.55 \mu \mathrm{m}$ AOD
VIIRS RGB

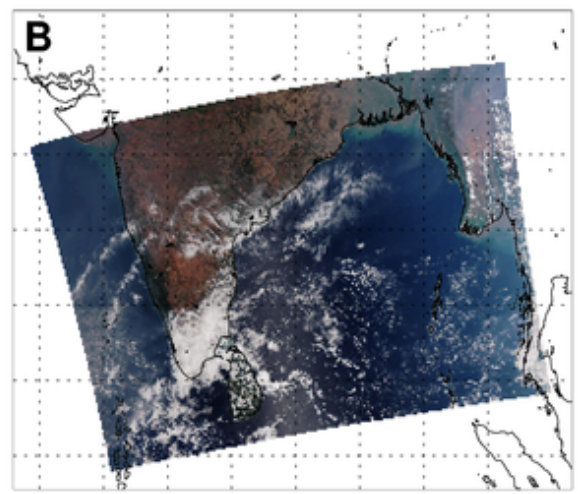

VIIRS EDR AOD

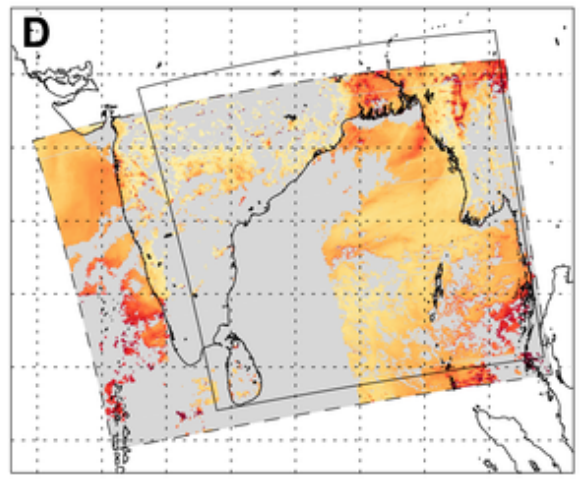

is

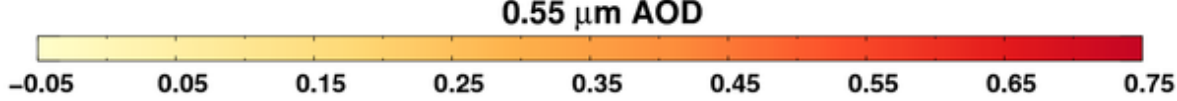

Figure 2. Overlap of MODIS and VIIRS centered on the Bay of Bengal, during a 5-minute period starting at 5 March 2013 at 07:35. (a and b) are true-color RGB images for MODIS and VIIRS. (c and d) are retrieved QA-filtered AOD at $0.55 \mu \mathrm{m}$ for the MODIS C6 (10 km) and VIIRS EDR $(6 \mathrm{~km})$ products. AOD are plotted based on published quality assurance recommendations for each product.

means in collocated grids, where each point denotes a seasonal mean calculated from both data sets.

Like the comparisons that Liu et al. (2014) show of MODIS C5 and VIIRS AOD, we see that the overall global patterns of AOD are similar between the two data sets. AOD is significantly smaller in the Southern Hemisphere (both land and ocean) for both products. There are hotspots for both data sets in southeast Asia, central America and central Africa. One change from the C5-based analysis is a larger coverage for MODIS in the southern oceans, due to allowing for aerosol retrieval under larger solar zenith angles. Otherwise, except for the complex cloud/aerosol belts east of Asia, MODIS and VIIRS seem to have converged over ocean, even compared to Liu et al. (2014). Primarily, this is because M_C6 has introduced wind speed dependence into the DT_O retrieval, which had already been included in the VIIRS-IDPS retrieval. In fact, the scatterplot (Fig. 4a) shows near one-to-one agreement for grid cells where both M_C6 and V_EDR provide data, with coefficent of determination $R^{2}=0.89$. Assuming the global seasonal mean to be the simple average of retrieved grid values (no accounting for surface area), for MAM 2013, both data sets indicate mean AOD over ocean of $\sim 0.13$.

Yet, over land, the differences remain large. Even with the upgrades to surface reflectance relationship for MODIS C6 (e.g., Levy et al., 2013), the AOD for V_EDR remains much higher than MODIS (Fig. 4b). The exceptions are near desert fringes and areas where surfaces tend to be brighter (Fig. 3c). Most of the difference patterns are consistent with those described by Liu et al. (2014). For collocated grid cells with over-land AOD during MAM (Fig. 4b), $R^{2}=0.58$, and the V_EDR product is biased high by 0.06 as compared to M_C6. We note that the high bias of VIIRS at high northern latitudes is associated with snow melt during the spring, and that there is a planned update to the operational VIIRS algorithm to be implemented by 2016 . 

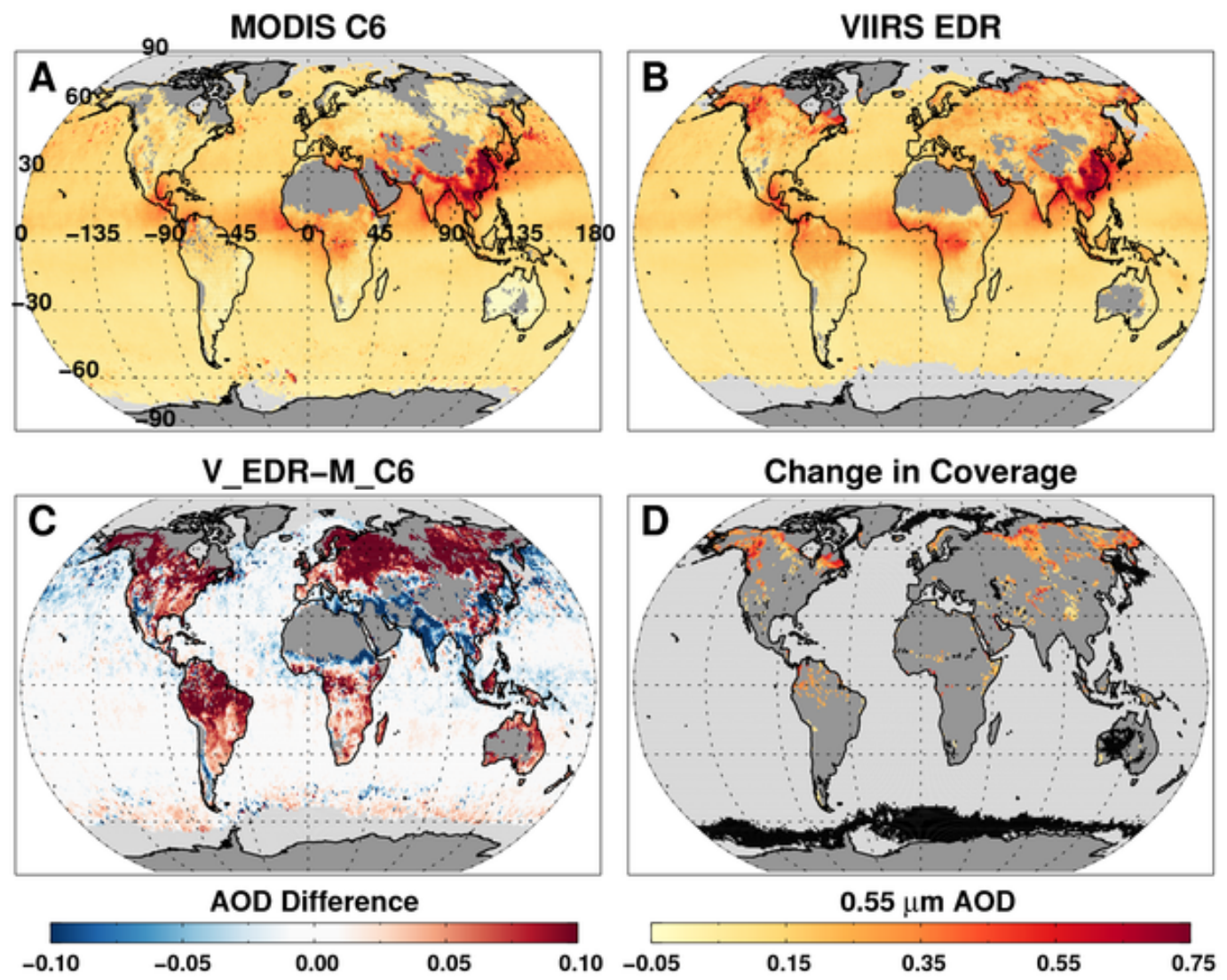

Figure 3. Spring (March-April-May) 2013 maps $\left(1^{\circ} \times 1^{\circ}\right)$ of QA-filtered mean AOD at $0.55 \mu \mathrm{m}$, derived from the MODIS C6 (a) and VIIRS EDR (b) products. (c) plots the difference between (b) and (a). (d) represents the "increased" coverage of VIIRS-EDR using AOD units, with reduced coverage plotted as black. Note that the seasonal AOD in a gridbox is the average of three monthly AODs, which in turn are derived as the average of daily AOD within each month. Published QA-filtering for each product is followed.
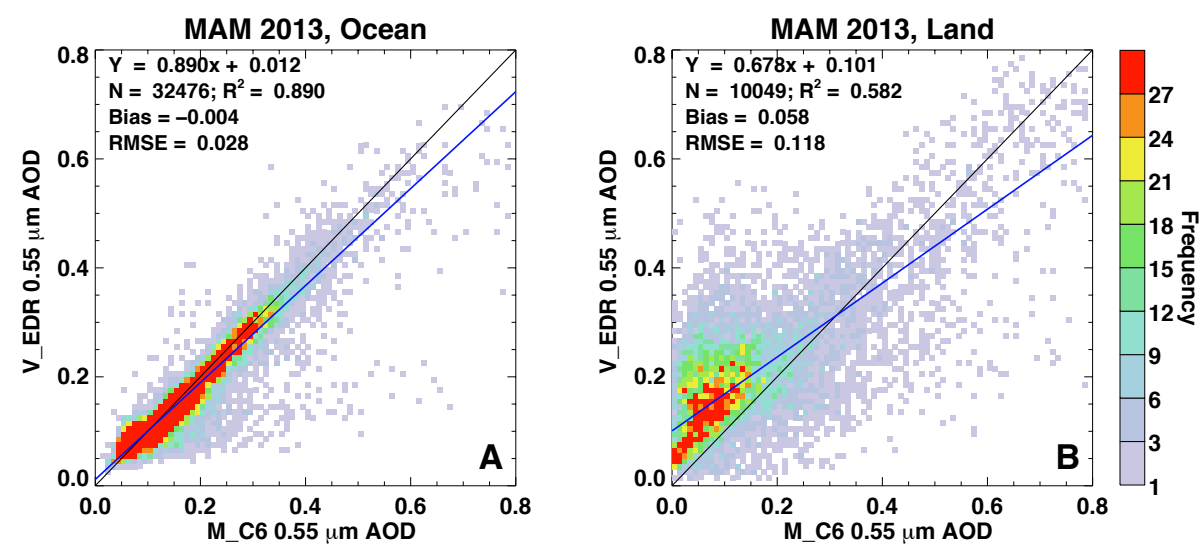

Figure 4. Comparison of mean AOD in collocated grids from the Spring 2013 maps (e.g., Fig. 2), for ocean retrievals (a) and land retrievals (b). Statistics (regression equation, number of collocated grids, correlation, bias and RMSE) are provided as text in each panel. 


\section{The MODIS-like algorithm}

Although both M_C6 and V_EDR products are meeting their prescribed goals for accuracy, the differences between them are too large to enable seamless creation of a CDR. However, based on the experience of the ocean color community (e.g., Franz et al., 2005, 2012), consistent algorithms may help. First, however, we have to create consistent input data.

\subsection{The Intermediate File Format}

A standard MODIS "granule" represents the swath collected over $5 \mathrm{~min}$ ( 288 per day). About 138 are daylight scenes suitable for aerosol retrieval. The combination of geolocation (angles, whether land/sea, etc.) and calibrated radiance/reflectance data are known as Level 1B (L1B) data and are stored in Hierarchal Data Format version 4 (HDF4). Calibrated data are separated into three files; one containing the $0.25 \mathrm{~km}$ bands (bands 1 and 2; B1 and B2), the second containing the $0.5 \mathrm{~km}$ bands (B3-B7, plus aggregated B1$\mathrm{B} 2$ ), and the third containing the $1 \mathrm{~km}$ bands (B8-B36, plus aggregated B1-B7). Standard VIIRS data cover $86 \mathrm{~s}$, are in HDF5 format, and each band is contained as a separate file. This leads to thousands of files per day, which, although an advantage for parallel computer processing, means that the VIIRS data are not easily used for MODIS-like processing.

To overcome some of these formatting differences, the NASA Atmosphere Science Investigator-led Processing System at the University of Wisconsin (A-SIPS; http://sips.ssec. wisc.edu/) created the Intermediate File Format (IFF) L1B files for both MODIS and VIIRS. For VIIRS, this meant joining native resolution (86 s) granules into 5-minute MODISlike granules, combining all M-bands and geolocation into a single file, filling in "bowtie-deleted" pixels, and finally archiving them in HDF4 format. The A-SIPS also created MODIS-based IFF files that included only $1 \mathrm{~km}$ resolution data (native $1 \mathrm{~km}$ plus aggregated B1-7 data) and similar geolocation information. The IFF data are essentially a "lowest common denominator", reporting only data at coarsest resolution ( $1 \mathrm{~km}$ for MODIS, and $0.75 \mathrm{~km}$ for VIIRS).

With IFF produced for both VIIRS and MODIS (e.g., V_IFF and M_IFF), a generic algorithm could theoretically be applied to either one. However, since the IFF only includes coarse resolution reflectance and geolocation data, not all inputs for the standard C6 algorithm are available. For example, the Wisconsin cloud mask (Frey et al., 2008) is not included for MODIS-IFF because the analogue for VIIRS is still under development. Thus, the lack of high-resolution reflectance data and upstream infrared-based cloud information will impact our various mask tests (clouds, ice/snow, underwater sediments and inland water) when we compare to standard M_C6 data. We envisioned, however, that this would provide a more level playing field when comparing the M_IFF and V_IFF outputs.

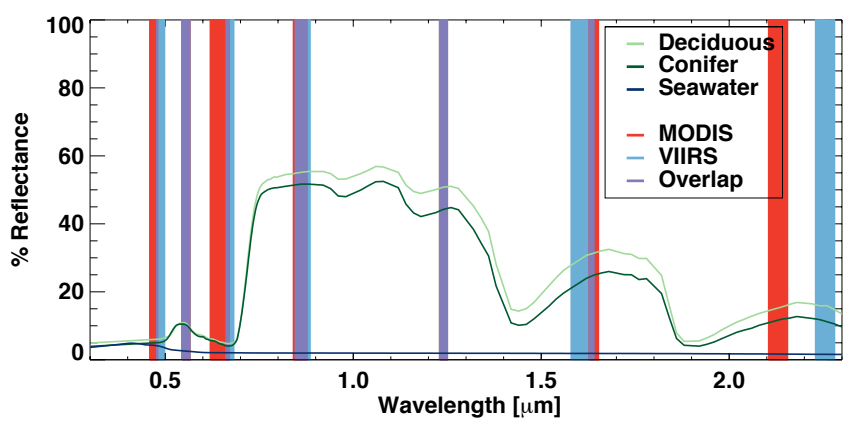

Figure 5. Bandwidths for MODIS (red) and VIIRS (blue) channel bands to be used for a the MODIS-like DT aerosol retrieval, overplotted with vegetation and seawater spectra. The two vegetation ("deciduous", “conifer") spectra are from JPL's ASTER spectral library (http://speclib.jpl.nasa.gov/), while the "seawater" is from USGS.

\subsection{Wavelength bands, LUTs and gas corrections}

We use the MODIS C6 LUTs and gas absorption formulas for the MODIS-like retrieval on the MODIS IFF inputs. However, because they are based on MODIS channels, we cannot simply apply these to the VIIRS IFF inputs, because not every MODIS-DT band has an exact VIIRS M-band equivalent (e.g., Table 3). Therefore, we use the nearest possible counterparts (M-bands within $\pm 0.03 \mu \mathrm{m}$ ), and model those for Rayleigh optical depth, gas absorption, and surface reflectance characteristics. Figure 5 displays the location and relative widths of the VIIRS bands compared to the MODIS bands.

Using the same strategies as described by Levy et al. (2013), the central wavelength (CW) and sea level Rayleigh optical depth (ROD) for all DT bands (MODIS vs. VIIRS) are listed in Table 4. Currently, only "in-band" response (relative spectral response, RSR $>1 \%$ ) is used for calculating these values. The RSR for MODIS is from the MODIS Characterization and Support Team (MCST; http: //mcst.gsfc.nasa.gov/), whereas the RSR for VIIRS comes from the "NG Band-Averaged RSRs" set from NOAA's Center for Satellite Applications and Research (STAR; http: //www.star.nesdis.noaa.gov/jpss/VIIRS.php). Including outof-band (OOB) response introduces less than $1 \mathrm{~nm}$ uncertainty to the CW for either MODIS or VIIRS, except for the VIIRS M3, where it leads to $2 \mathrm{~nm}$ uncertainty.

We created aerosol LUTs for VIIRS using the same methodology and tools used for MODIS DT algorithm (e.g., Levy et al., 2007a, b; Remer et al., 2008). A combination of MIEV (Wiscombe, 1991) and RT3 (Evans and Stephens, 1991) was used for DT_L, and the Ahmad and Fraser (1982) code was used for DT_O. All improvements made for C6 (Levy et al., 2013) were also applied for creating LUTs for VIIRS, including allowing for solar zenith angles up to $84^{\circ}$. While ROD dependence is modeled explicitly, aerosol model properties (refractive indices, size distributions) are assumed 
Table 4. Characteristics of MODIS and VIIRS bands used for DT retrieval, including central wavelength (CW) and Rayleigh Optical Depth (ROD).

\begin{tabular}{llllll}
\hline MODIS Band \# & MODIS CW $(\mu \mathrm{m})$ & MODIS ROD & VIIRS Band \# & VIIRS CW $(\mu \mathrm{m})$ & VIIRS ROD \\
\hline B3 & 0.466 & 0.1918 & M3 & 0.488 & 0.1602 \\
B4 & 0.554 & 0.0945 & M4 & 0.551 & 0.0976 \\
B1 & 0.646 & 0.0508 & M5 & 0.670 & 0.0440 \\
B2 & 0.856 & 0.0162 & M7 & 0.861 & 0.0160 \\
B5 & 1.242 & 0.0036 & M8 & 1.239 & 0.0037 \\
B6 & 1.629 & 0.0012 & M10 & 1.601 & 0.0013 \\
B7 & 2.113 & 0.0004 & M11 & 2.257 & 0.0003 \\
\hline
\end{tabular}

unchanged for the small wavelength changes. For example, the properties assumed for $0.49 \mu \mathrm{m} \mathrm{M} 3$ on VIIRS are copied from $0.47 \mu \mathrm{m}$ B3 on MODIS.

Methods for deriving equations used for correcting gas absorption (e.g., $\mathrm{H}_{2} \mathrm{O}, \mathrm{O}_{3}, \mathrm{CO}_{2}$, etc.) are described by Levy et al. (2013). The Line-By-Line RT model (Clough et al., $1992,2005)$ is used for deriving equation coefficients. The spectral shifts from MODIS to VIIRS do matter. For example, due to the Chappius band, the VIIRS M3 band has nearly double the ozone absorption as the MODIS B3. For a standard atmosphere profile, ozone optical depths are 0.007 vs. 0.003 . While the difference in simulated TOA reflectance may be only on the order of 0.001 (for typical reflectance of 0.2 ), due to the sensitivity of reflectance to aerosol phase function and scattering, this may lead to error of 0.01 in retrieved AOD. Even more significant are the differences between B6 vs. M10, and B7 vs. M11, where carbon dioxide and/or water vapor are significant absorbers. With non-linear response to all bands in the inversion, not correctly accounting for gas absorption can lead to $\sim 0.02$ or more bias in aerosol retrieval.

\subsection{Cloud masking, pixel selection and aggregation}

The strategies for masking, selecting and aggregating pixels for the DT algorithm for MODIS C6 are described already (e.g., Levy et al., 2013, 2009; Martins et al., 2002). However, since there is not yet an analogue of the "Wisconsin" cloud mask (e.g., MxD35; Frey et al., 2008) for VIIRS, we only apply the internal "aerosol" cloud masks (e.g., $3 \times 3$ pixel spatial variability and visible/1.24/1.38 $\mu \mathrm{m}$ tests) to the VIIRS IFF data. This means that, due to lack of three IR-based tests (e.g., Levy et al., 2013), there will be degradation of cloud detection ability. To ensure fair comparison of our ML_V and ML_M products, we also ignore MxD35 for the MODIS IFF retrieval. Although there are differences in pixel resolution between MODIS C6 inputs (e.g., $0.5 \mathrm{~km}$ ), M_IFF $(1 \mathrm{~km})$ and V_IFF data $(0.75 \mathrm{~km})$, as well as slight wavelength shifts, we have assumed the M_C6 cloud mask detection thresholds and M_C6 thresholds for detecting underwater sediments and ice/snow. We use the same ancillary data, including analyses from the Global Data Assimilation
System (GDAS; Kanamitsu, 1989) for prescribing water vapor, ozone and wind speed and the same global "water mask" (Carroll et al., 2009).

The M_C6 aerosol products are at $10 \mathrm{~km}$ (at nadir) resolution, which are based on boxes of $20 \times 20$ pixels at $0.5 \mathrm{~km}$ resolution. Here, we chose to keep the product spatial resolution similar, so that the ML_M aerosol product is $10 \mathrm{~km}$, based on $10 \times 10$ boxes of pixels at $1 \mathrm{~km}$ resolution. The ML_V aerosol product is $7.5 \mathrm{~km}$, also based on $10 \times 10$ boxes of pixels. After cloud masking, the DT algorithm includes a residual filter intended to reduce contamination from cloud shadows and bright clouds. For MODIS C6, after sorting by reflectance, only the interval $25-75 \%$ are kept for the retrieval over ocean, and $20-50 \%$ are kept for use over land. This means when working on $20 \times 20=400$ pixels for C6, that there will be at most 200 pixels over ocean or 120 pixels over land. If any pixels have already been masked due to clouds or other target issues, then there will be fewer. Over ocean, the MODIS DT algorithm requires 10 pixels to attempt aerosol retrieval, and more than 20 to meet requirements for high retrieval confidence. Over land, these requirements are 12 and 50. As we have moved to operating on $10 \times 10=100$ pixels for either IFF data set, the maximum available becomes 50 pixels over ocean or 30 over land. Therefore, the minimum number of pixels for retrieval and for meeting QA requirements must be redefined. Simply dividing by four would lead to non-integers, so we require 3 pixels (for retrieval) and 4 pixels (for confidence) over ocean, and 3 pixels (for retrieval) and 12 pixels (for confidence) over land.

Since the $10 \times 10$ thresholds are not integer divisors of those required by $20 \times 20$, and having fewer pixels in general impact signal to noise, we expect differences between MODIS C6 and the ML_M retrieval. This is in addition to having no IR-based cloud masking, as well as expected small impact from having coarser spatial resolution for $3 \times 3$ cloud masking, and coarser $(1 \mathrm{~km})$ resolution for snow/ice and other tests.

\subsection{Land surface reflectance assumptions}

While we have assumed that neither aerosol reflectance properties nor visible-based cloud masking algorithms should 
change much with respect to small spectral shifts (MODIS vs. VIIRS), we cannot assume the same is true for assumptions of land surface optical properties (e.g., Fig. 4). For MODIS, Levy et al. (2007b) derived band-to-band relationships for surface reflectance, each described by a combination of ratios (slopes) and corrections (offsets). Specifically, the nominal slopes were set at 0.53 and 0.49 , for B3/B7 and $\mathrm{B} 1 / \mathrm{B} 3$, respectively, but were functions of scattering angle and NDVI_SWIR (shortwave Normalized Difference Vegetation Index - a measure of surface "greenness"). The values were considered "global", so they would be representative of many vegetated surfaces, and would minimize systematic bias in retrieved AOD. However, the standard deviation of the band ratios was large.

Under typical reflectance spectra for green vegetation, Fig. 5 shows that surface properties within VIIRS bands are different from those in MODIS bands. For the blue band, reflectance is larger in VIIRS M3 $(0.49 \mu \mathrm{m})$ as compared MODIS B3 $(0.47 \mu \mathrm{m})$, and yet in the red band, reflectance is smaller in VIIRS M5 $(0.67 \mu \mathrm{m})$ as compared to MODIS B1 $(0.65 \mu \mathrm{m})$. Clearly, surface reflectance ratios assumed for MODIS will not work for VIIRS. Although the V_EDR uses VIIRS-specific ratios derived from VIIRS-measured radiances (Jackson et al., 2013), Liu et al. (2014) showed that the ratio's characterization could benefit from additional (MODIS-like) information of surface greenness and scattering angle. Since, a complete MODIS-like surface reflectance relationship requires a comprehensive atmospheric correction (e.g., Levy et al., 2007a) that has not been performed yet, we have assumed the ratios used for the V_EDR without benefit of any angle or greenness dependency. Specifically, we assume ratios of 0.56 for M5/M11 and 0.65 for M3/M5 (Jackson et al., 2013). Thus, for this version of IFF retrieval, we may see biases over some regions.

\section{Results}

Here we compare the MODIS-like products on MODIS and VIIRS, with each other and with the standard MODIS C6 and VIIRS_EDR products.

\subsection{AOD: granule and daily imagery}

Figure 6 shows the granule (5 March 2013 at 07:35 UTC) retrievals from ML_M and ML_V, comparable with the M_C6 and V_EDR imagery presented in Fig. 2. The MODIS-like $\mathrm{QA}$ requirement is $\mathrm{QAC}=3$ over land and $\mathrm{QAC} \geq 1$ over ocean. As intended, the ML_V is more similar to the ML_M (and thus to M_C6) than the V_EDR was to M_C6. Over land, where both retrieve, the AOD values are closer, including the region over Bangladesh identified in Fig. 2 where M_C6 and V_EDR AOD differed by $\sim 0.3$. However, there is still some discrepancy in coverage, especially over eastern India, which is retrieved as near-zero AOD by ML_M, but still not retrieved by ML_V. It appears that the issue is identification of "bright" scenes not suitable for retrieval. The retrieval is set up to degrade results (to lower QAC values) when the observed reflectance in SWIR channel (2.11 for MODIS, $2.26 \mu \mathrm{m}$ for VIIRS) is greater than 0.25 . Due to the differences in this wavelength band, the decision to use or not to use a particular ground location may vary between retrievals.

Figure $7 \mathrm{a}$ and $\mathrm{b}$ plots the MODIS-like retrievals (ML_V and ML_M) for 29 May 2013 (RGB in Fig. 1). This date was chosen for significant overlap of MODIS and VIIRS orbits along with aerosol hotspots that could be visually compared. Data are gridded to $1^{\circ} \times 1^{\circ}$ boxes (similar to MODIS Level 3 ), and filtered by QAC values. Clearly, VIIRS has greater coverage than MODIS, so Fig. 7c shows aggregation for when limiting VIIRS retrieval to a MODIS-like swath width (constraining to sensor zenith angle $<60^{\circ}$ ).

\subsection{AOD: Level 2 retrieval statistics}

We applied the ML algorithm to both MODIS and VIIRSIFF, for the entire Spring (MAM) 2013 season. Table 5 presents some statistics for the resulting along-orbit (Level 2) data, separately over ocean and land. When we consider the number of possible retrievals (daytime for a particular surface), the "non-filtered retrieval fraction" indicates how many are populated with valid AOD (dark, cloud-free, nonglint, etc), while the "QA-filtered retrieval fraction" represents the subset having higher confidence. Let us denote the QA-filtered retrieval fraction as the "retrieval fraction", or "retrievability", which depends on pixel resolution (Remer et al., 2012), masking algorithms (cloud, surface, ice/snow, etc.), and QA assignment (e.g., Levy et al., 2013). A consistent algorithm would be expected to make similar choices, so that under the same observing conditions, there would be similar retrieval fraction. We will discuss retrievability further in Sect. 4.4.

The last two columns in Table 5 report two different calculations of mean global AOD. The first of these is the simple average of all QA-filtered pixels, and can be thought of representing the sampling of the instrument, convolved with choices of the retrieval algorithm. This "pixel-weighted" view of the world is by definition, clear-sky biased (Levy et al., 2009). The latter is computed by first creating a Level 3-like product (e.g., Fig. 3) and then taking the simple average of all grid values (no weighting by surface area). Thus, observed differences in L3 global means convolve differences in retrieved L2 AOD with the sensor sampling and algorithm retrievability. Interestingly, differences between MODIS and VIIRS may be more or less (and of different sign) whether considering the Level 2 or Level 3 aggregations (Levy et al., 2009). We will discuss global mean AOD further in Sect. 4.3.

Over-ocean, the global QA-filtered mean AOD from the ML_M algorithm $(=0.11)$ is similar to M_C6. With the 
MODIS-like on MODIS

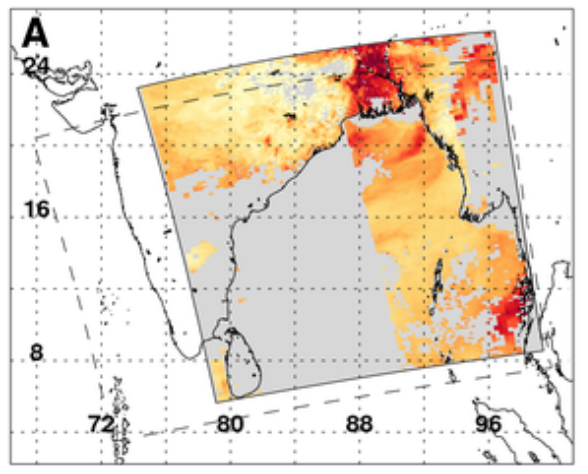

\section{MODIS-like on VIIRS}

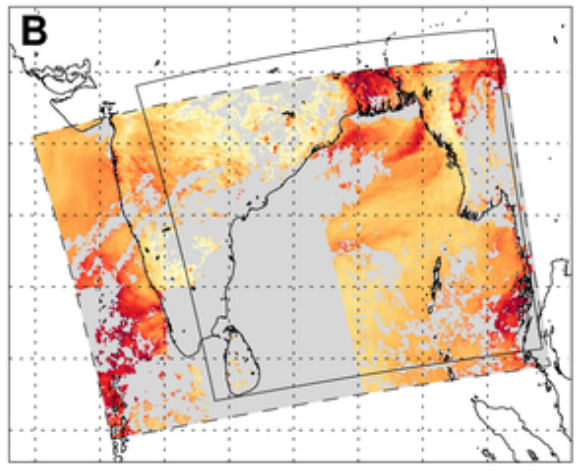

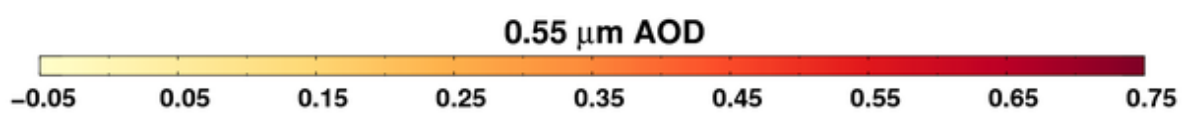

Figure 6. QA-filtered AOD at 0.55 $\mu$ m over the Bay of Bengal on 5 March 2013 at 07:35, retrieved with MODIS-like algorithm on (a) MODIS (at $10 \mathrm{~km}$ ) and (b) VIIRS (at $7.5 \mathrm{~km}$ ). This is the same observational overlap as pictured in Fig. 2.
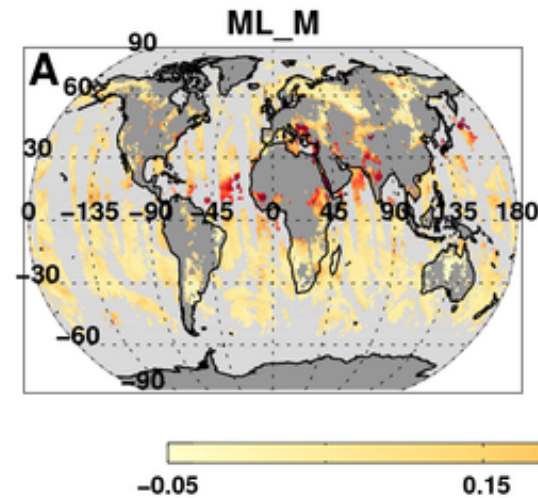

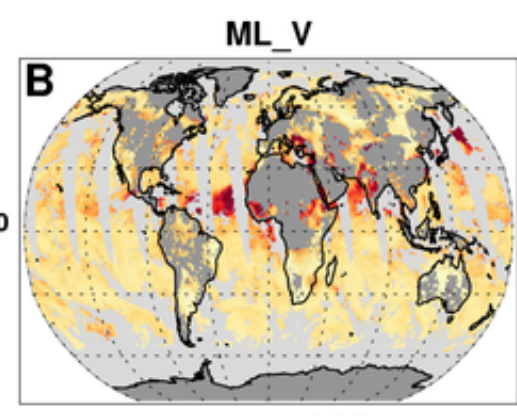

$0.55 \mu \mathrm{m} \mathrm{AOD}$

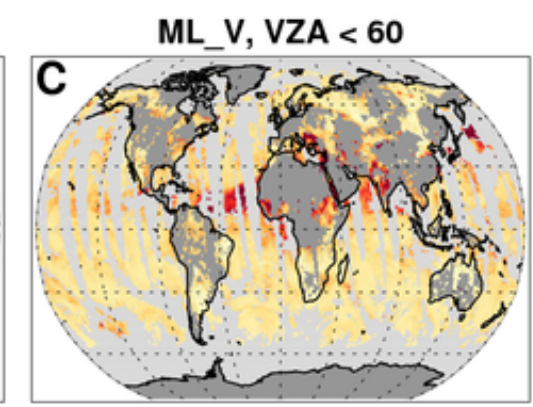

0.55

0.75

Figure 7. AOD at $0.55 \mu \mathrm{m}$, retrieved using MODIS-like algorithm on MODIS (a) and VIIRS (b), created from all orbits during 29 May 2013 (see Fig. 1). (c) approximates the MODIS coverage by reducing the VIIRS swath to sensor view angles less than $60^{\circ}$.

ML_V data set, it jumps by 0.02 or nearly $20 \%$, even for the MODIS-width-like swath. The V_EDR value is 0.12 . Figure 8 compares relative histograms (normalized to the total QA-filtered retrievals) of the QA-filtered AOD. Over ocean (top), the overall histograms are similar, but the ML_V and ML_V60 histograms are shifted slightly towards higher AOD, suggesting that the difference in the ML_M and ML_V AOD retrievals are due to a slight increase for every L2 pixel's value rather than adding a few high values. The most significant difference may be that the V_EDR does not provide data in the smallest bin (between -0.05 and 0.00 ), whereas the MODIS algorithm allows for high quality retrievals of exactly zero (Levy et al., 2013).

Over land, all MODIS or MODIS-like products estimate a global (Level 2) mean around 0.17, differing by less than 0.01 . These are all less than the V_EDR mean of 0.20 . The histograms for land (Fig. 8b) retrievals show a very similar distribution for ML_M and ML_V, with large differences compared to the V_EDR. The MODIS DT algorithms allow retrievals of zero and small negative AOD (to -0.05) where the V_EDR algorithm does not (see Fig. 8, bottom).

Whether over land or over ocean, reduced swath version of ML_V (ML_V60) have generally the statistics as the full swath versions. This means that the discrepancies between ML_V and the MODIS retrievals are not due to the increased VIIRS sampling.

\subsection{AOD: seasonal maps and statistics}

Figures 9 and 10 follow from Figs. 3 and 4, showing seasonal (MAM, Spring 2013) maps and scatterplots of $1^{\circ} \times 1^{\circ}$ AOD, for ML_M and ML_V data sets. Global means (equal weighting for each grid cell) are reported as the last column in Table 5.

Based on simple averaging of the $1^{\circ} \times 1^{\circ}$ grids, the global mean for ML_M is within 0.01 of M_C6. Figure 9d plots the difference between ML_M (Fig. 9a) and M_C6 (Fig. 3a) 
Table 5. Spring 2013 (March-April-May) statistics of QA-filtered AOD, retrieved over ocean (top) and land (bottom). QA-filtering for the MODIS and MODIS-like products is QAC $\geq 1$ over ocean and QAC $=3$ over land, whereas for the VIIRS EDR it is QAC $=3$ only for both surfaces.

\begin{tabular}{llllllll}
\hline Product & $\begin{array}{l}\text { Land or } \\
\text { Ocean }\end{array}$ & $\begin{array}{l}\text { AOD } \\
\text { resolution } \\
(\mathrm{km})\end{array}$ & $\begin{array}{l}\text { Non-filtered } \\
\text { retrieval } \\
\text { fraction }\end{array}$ & $\begin{array}{l}\text { QA-filtered } \\
\text { retrieval } \\
\text { fraction }\end{array}$ & $\begin{array}{l}\text { Number of } \\
\text { QA-filtered } \\
\text { retrievals }\end{array}$ & $\begin{array}{l}\text { Mean AOD } \\
\text { (pixel } \\
\text { weighted) }\end{array}$ & $\begin{array}{l}\text { Mean AOD } \\
(\text { equal } \\
\left.1^{\circ} \times 1^{\circ}\right)\end{array}$ \\
\hline M_C6 & Ocean & 10 & 0.187 & 0.183 & $4.24 \times 10^{7}$ & 0.115 & 0.127 \\
ML_M & Ocean & 10 & 0.146 & 0.145 & $3.34 \times 10^{7}$ & 0.113 & 0.122 \\
ML_V & Ocean & 7.5 & 0.176 & 0.173 & $1.25 \times 10^{8}$ & 0.134 & 0.148 \\
ML_V60 & Ocean & 7.5 & 0.171 & 0.169 & $1.07 \times 10^{8}$ & 0.132 & 0.144 \\
V_EDR & Ocean & 6 & 0.352 & 0.123 & $1.41 \times 10^{8}$ & 0.122 & 0.130 \\
\hline M_C6 & Land & 10 & 0.140 & 0.069 & $6.63 \times 10^{6}$ & 0.175 & 0.146 \\
ML_M & Land & 10 & 0.133 & 0.074 & $6.97 \times 10^{6}$ & 0.168 & 0.154 \\
ML_V & Land & 7.5 & 0.132 & 0.074 & $1.97 \times 10^{7}$ & 0.169 & 0.160 \\
ML_V60 & Land & 7.5 & 0.132 & 0.074 & $1.71 \times 10^{7}$ & 0.170 & 0.158 \\
V_EDR & Land & 6 & 0.289 & 0.075 & $3.33 \times 10^{7}$ & 0.199 & 0.217 \\
\hline
\end{tabular}

maps, showing that most grids also have differences (of less than 0.01). However, it is interesting that global AOD is reduced over ocean (from 0.127 to 0.122 ), but is increased over land (from 0.146 to 0.154 ). Even more interesting is that the ML_M-M_C6 differences vary whether using gridded data, as compared to using along orbit (L2) data. In fact, they are of opposite sign depending on surface. Whereas the global over-ocean AOD reduced under either averaging protocol, the global over-land AOD is increased under gridded averaging, but decreased under L2 averaging. Clearly, there is a complex interplay between the concepts of aggregating and averaging, between clear-sky bias (e.g., Levy et al., 2013) and retrievability (e.g., Remer et al., 2012).

Figure 9d shows that whether over ocean or land, the biggest per-grid differences are along the mid-latitude storm belts, mostly driven by differences in cloud masking. These arise from the combination of coarser pixel resolution (1 vs. $0.5 \mathrm{~km}$ ) and lack of thermal infrared-based (e.g., MxD35) cloud mask information, together causing systematic bias in pixel selection and aggregation for retrieval (e.g., Martins et al., 2002). Over ocean, although this makes little or no difference for most grid cells (e.g., Fig. 10a), there are some grid cells with much larger differences (tending toward reduced AOD). The result is that $R^{2}=0.884$ is less than unity and that gridded data tends to show larger differences between ML_V and M_C6 than does along-orbit (Level 2) retrievals. By substituting the full MxD35 cloud mask (from M_C6) into the ML_M retrieval (not shown explicitly here), we confirmed that the cloud mask is the major culprit.

Over land, while reduced-resolution cloud masking contributes to the discrepancies between ML_M and M_C6, the more pertinent issue is the resolution's impact on surface feature masking. The coarser resolution impacts ice/snow masking, in that sub-pixel snow can elude a coarse $(1 \mathrm{~km})$ resolution snow mask. This will tend to lead to higher-retrieved
AOD. Similarly, sub-pixel inland water (and coastlines) can elude a coarser-resolution inland water mask, leading to lower-retrieved AOD. Although we do not describe every grid and how it contributes to global mean, it is clear that both resolution and upstream information do matter. Interestingly, however, even with an overall high bias, the R-squared for land grids is extremely high $\left(R^{2}=0.969\right.$; Fig. 10b).

We now move from the ML_M to the ML_V, for which presumably, the differences in upstream information (no Wisconsin cloud mask or thermal IR, and more similar resolutions) should be less important. Figure 9e plots the difference between the ML_V and ML_M maps, and Fig. 10c and d compare ML_V with ML_M for collocated grids over ocean and land.

Certainly, the bias pattern for ML_V compared to ML_M is significantly different than for the V_EDR compared to the M_C6 (even accounting for the small ML_M vs. M_C6 biases). Since Fig. 9f shows that there is essentially no difference between the reduced swath (Fig. 9c) and the entire swath (Fig. 9b), we cannot blame the bias pattern of Fig. 9e on VIIRS having a wider swath with more oblique viewing angles. At least for this particular season, the differences in sampling (e.g., Colarco et al., 2014) do not influence the gridded or global means.

Thus, over ocean (Figs. 9e and 10c), the use of the ML algorithm on VIIRS has introduced a bias as compared to MODIS, which was not observed in the original comparison between the V_EDR and M_C6. The R-squared between ML_V and ML_M for collocated grids is only slightly lower $\left(R^{2}=0.86\right)$, but the bias is significantly greater $(B=0.025)$ than was seen for the V_EDR. We do note, however, that part of this reduction in correlation has come from the $13 \%$ increase in the number of collocations (from 32476 to 36742 ), primarily found over the far southern and northern oceans. These regions are difficult to retrieve (e.g., Shi et al., 2011), 

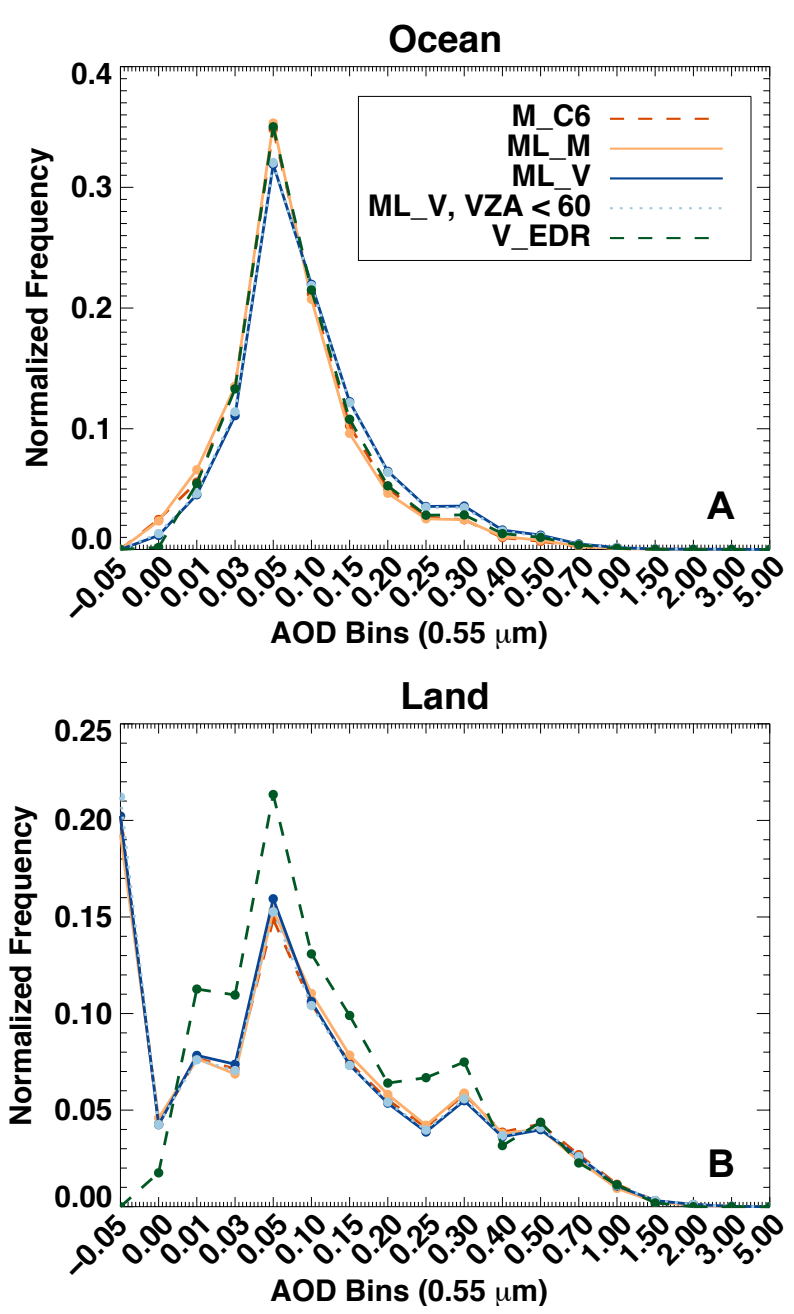

Figure 8. Spring 2013 (March-April-May) relative frequency histograms of QA-filtered AOD, retrieved over ocean (top) and land (bottom). Note the non-uniform bin width, and that negative values are allowed in the MODIS C6 and MODIS-like data sets over land. See Table 5 for the number of QA-filtered pixels in each data set.

and correlation improves if they are not included in the scatterplot. However, Fig. 9e shows that the bias is present over all of the global oceans, and remains even if the far northern and southern oceans are excluded.

On the other hand, the ML_V retrieval over land, (Figs. 9e and $10 \mathrm{~d}$ ), unequivocally reduces regional biases by an order of magnitude as compared to V_EDR, and the global mean is much closer to either ML_M or M_C6. The Rsquared for ML_M and ML_V collocated grids is impressive $\left(R^{2}=0.935\right)$ with negligible (0.006) bias.

From the combination of Figs. 9 and 10, it is clear that ML_V provides a different view of the world than the V_EDR. The ML_V world looks much more like MODIS's over land, but it has a $20 \%$ high bias over ocean.

\subsection{AOD: retrievability}

As a function of geography, geometry and the state of the atmosphere, can we quantify the chance that a particular algorithm will derive a high-confidence value for AOD? In terms of where and when seasonal mean AOD are derived, we focus on the concept of retrievability, in order to evaluate whether the algorithms have made similar choices under similar conditions.

Table 5 shows general agreement for the non-filtered retrieval fraction between all versions of the MODIS-like algorithm, ranging between 0.146 and 0.187 over ocean and 0.132 and 0.140 over land. In other words, approximately $15-19 \%$ of all $10 \mathrm{~km}$ (or 7.5 ) km boxes are retrieved over land, with $13 \%$ over ocean. This value is much less than the V_EDR, which reports an AOD value in $35.2 \%$ of all retrieval boxes over ocean and $28.9 \%$ over land. However, when it comes to assigning confidence to the retrieval, the resulting retrieval fraction converges somewhat. Over ocean, nearly $99 \%$ of the retrieved values meet QAC thresholds under MODIS-like logic, but only a third meet the stricter V_EDR requirements. Therefore, after QA-filtering, the retrieval fraction for the V_EDR actually becomes lower $(0.123)$ than any MODIS or MODIS-like retrieval $(\geq 0.145)$. There is negligible difference between the full ML_V and (the reduced swath of) the ML_V60. Over land, after QAC filtering, all algorithms retrieve about $7 \%$.

For this section, let us use the ML_M as a baseline. Figure 11 shows that although over-ocean retrieval fraction averages near $15 \%$ and over-land near $7 \%$, the retrieval fraction differs greatly by region. As expected, sparse or no retrieval is made over the deserts and snow surfaces. Yet, interestingly, the largest retrieval fractions are adjacent to deserts, including pre-monsoon India (Thar), southern Africa (Kalahari) and the Sahel (Sahara). These regions have low rainfall and cloud cover during MAM 2013. Over ocean, while the retrieval fraction is more balanced, there tends to be lower retrieval fraction over cloudy areas (ITCZ and midlatitude storm tracks).

Figure 12 plots global retrieval fraction from the three other algorithms as compared to ML_M (Fig. 11). The top row shows difference maps, while the middle and bottom rows are scatterplots comparing the $1^{\circ}$ grids, for ocean and land, respectively. Left, middle and right columns show M_C6, ML_V and V_EDR as compared to ML_M.

Among the MODIS-like products, Table 5 showed that the largest global retrievability difference was between the M_C6 (0.18) and ML_M (0.14) over ocean. Examining Fig. 12a and d, this retrievability difference is nearly everywhere, in that all original M_C6 data had $\sim 0.04$ greater retrieval fraction than ML_M. However, looking closer, we see that there are two regimes contrary to the high bias. Close to coastlines (e.g., the west coasts of North America and Africa), there is not a large difference between the two data sets. These are the grids that make up the arm that nearly 

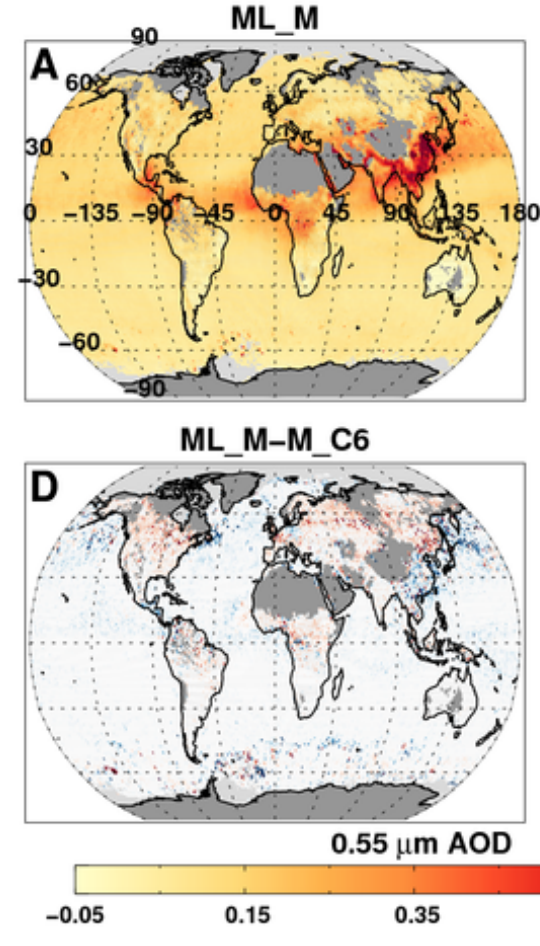

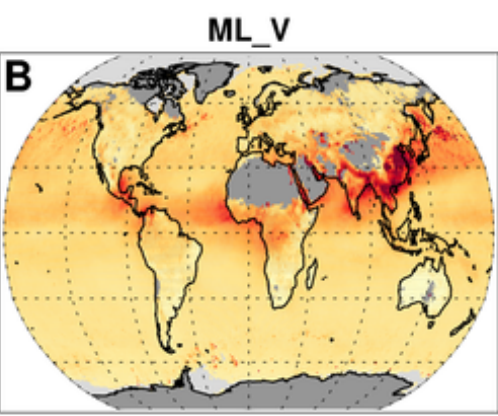

ML_V-ML_M
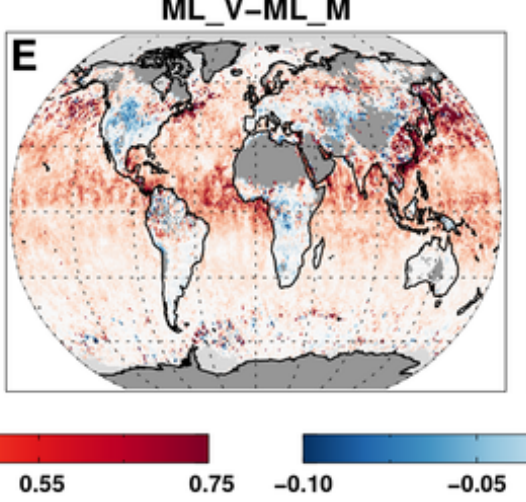
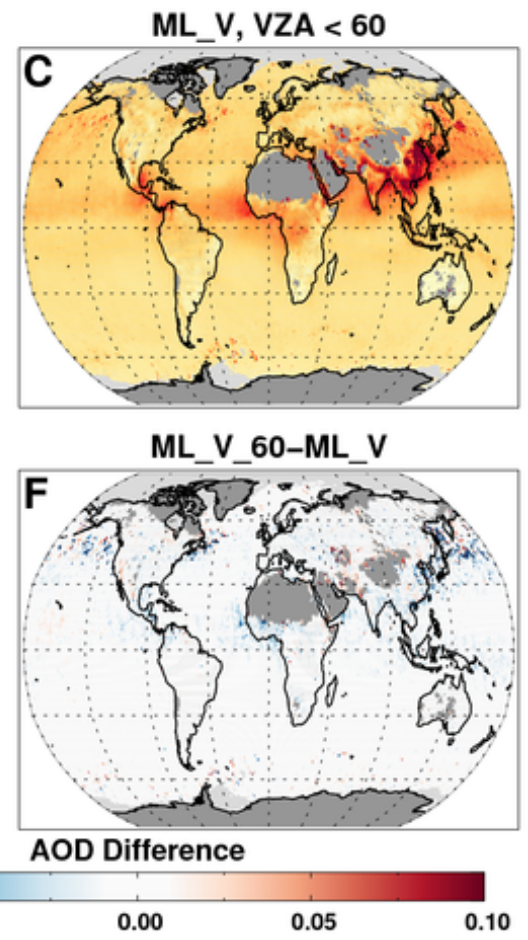

Figure 9. Spring 2013 (March-April-May) maps $\left(1^{\circ} \times 1^{\circ}\right)$ of QA-filtered mean AOD, retrieved from the MODIS-like algorithm on MODIS (a) and VIIRS (b) IFF data sets. (c) is the seasonal plot for VIIRS but subsetted to approximate MODIS coverage (view zenith angle $<60^{\circ}$ ). (d) is the difference between the ML on MODIS and the MODIS C6 product (Fig. 2a), whereas (e) is the difference between the two MODIS-like data sets (b)-(a). Finally (f) shows negligible difference between seasonal means derived from the reduced swath and entire VIIRS swath (c)-(b). See Fig. 2.

follow the one-to-one line on Fig. 12d. For the bulk of the ocean, however, the M_C6 has significantly greater retrievability (slope $=1.21$ ). That is, the original M_C6 had $20 \%$ more retrievals than does the degraded ML_M, regardless of retrieval fraction. With a lower resolution $(1 \mathrm{~km})$ spatial variability test, the ML_M is less able to identify discrete clouds in a $10 \mathrm{~km}$ box, and is more likely to throw out the entire retrieval (Martins et al., 2002; Remer et al., 2012). As AOD tends to be larger near cloud edges, reduced retrieval fraction (from increased cloud masking) reduces the chance of retrieving higher AOD near clouds. As a result, there are fewer high AOD retrievals, so that nearly every grid cell has lower AOD for the ML_M product than for the M_C6.

Over land, Table 5 indicated that the original M_C6 was more likely to have retrieved an AOD value than the degraded ML_M (0.14 vs. 0.13) but was less likely to have retrieved a high-confidence value (0.069 vs. 0.074). Figure 12a and $g$ show that the sign of the retrieval fraction difference is not the same over all grids. Most land grids are retrieved with higher frequency in M_C6 than they are in ML_M. This is in part to better cloud masking, but also that the M_C6 is better at identifying inland and ephemeral water as well as ice and snow. The better masking creates a larger chance for aerosol retrieval upon the remaining pixels, but also a larger chance to degrade confidence because it has identified poorer retrieval conditions. At the same time, better removal of snow/ice (a bright surface) will lead to a lower retrieved AOD, whereas better removal of inland water (very dark surface) may lead to a higher retrieved AOD.

Turning to the ML_V, we see that over ocean, the retrieval fraction is greater than ML_M by 0.03 , which means that there are $16 \%$ more QA-filtered AOD values. However, instead of being over nearly all global grids, Fig. $12 \mathrm{~b}$ indicates a zonal pattern to the retrieval differences, with larger differences in the tropics as compared to the northern and southern oceans. The zonal pattern is also well correlated with the AOD differences (Fig. 9e). While the differences in spatial resolution $(750 \mathrm{~m}$ vs. $1 \mathrm{~km})$ definitely will impact the cloud mask, and therefore retrievability, the patterns tend to suggest that something else may be responsible. Even so, the relationship between $\mathrm{ML} \_\mathrm{V}$ and $\mathrm{ML} \_\mathrm{M}$ retrieval fraction is still strong $\left(R^{2}=0.90\right)$. Over land, Fig. $12 \mathrm{~h}$ shows that global retrieval fraction is nearly identical between ML_M and ML_V (0.074), and is nearly one-to-one over most grid cells $\left(R^{\overline{2}}=0.96\right)$. There is some regional variability, resulting in some scatter about the one-to-one line. There does not appear to be a strong relationship between larger differences in retrieval fraction and larger differences in retrieved AOD. The ML_V and ML_M appear to be making similar choices when it comes to retrieving aerosol over land. 

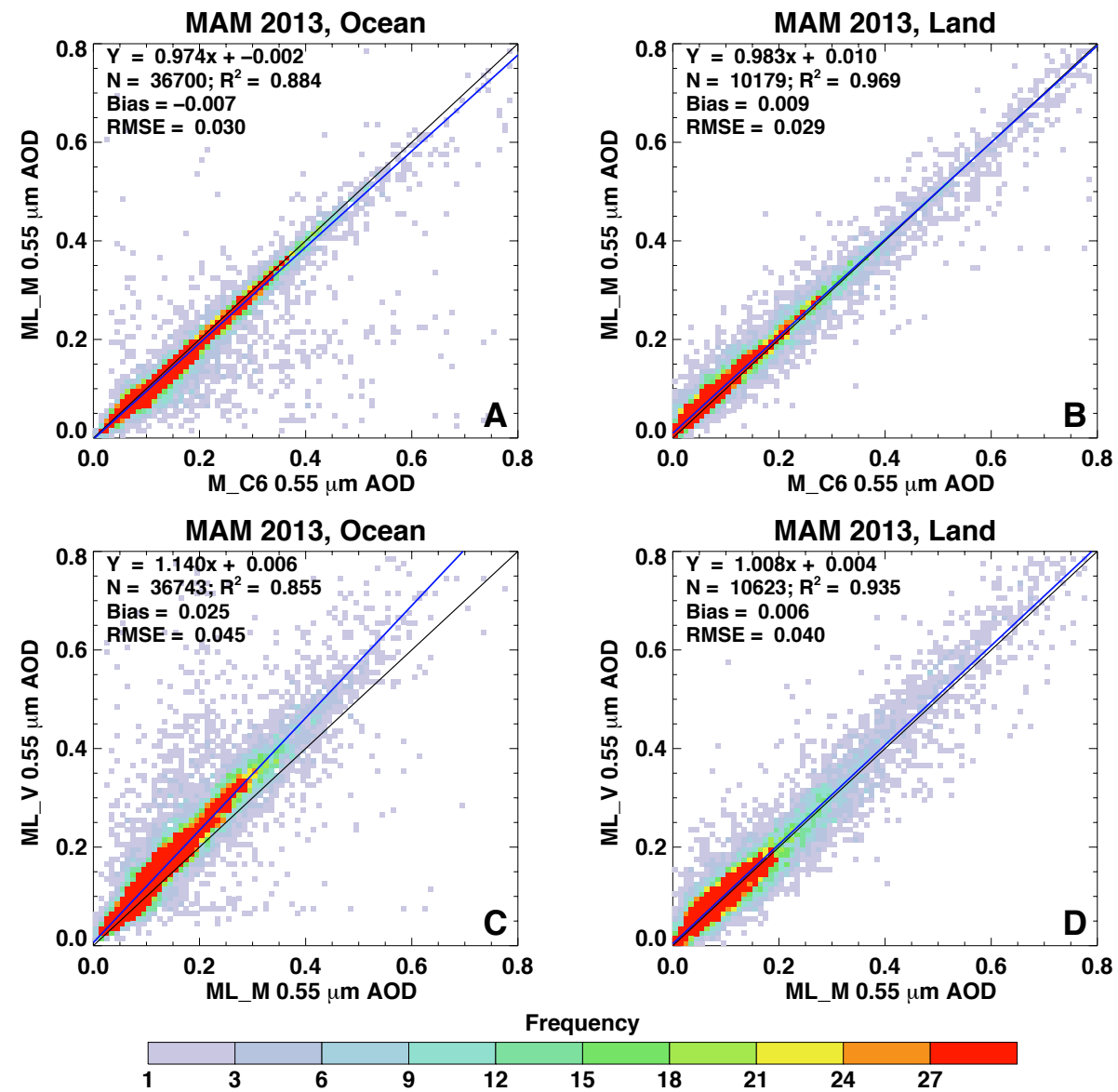

Figure 10. Comparison of mean AOD in collocated grids from the Spring 2013 maps (e.g., Fig. 7), for ocean retrievals (a and c) and land retrievals (b and $\mathbf{d}$ ). The top panels (a and $\mathbf{b}$ ) are MODIS-like on MODIS compared to the MODIS C6, and the bottom panels (c and $\mathbf{d}$ ) are for ML_V vs. ML_M. Statistics (regression equation, number of collocated grids, correlation, bias and RMSE) are provided as text in each panel.

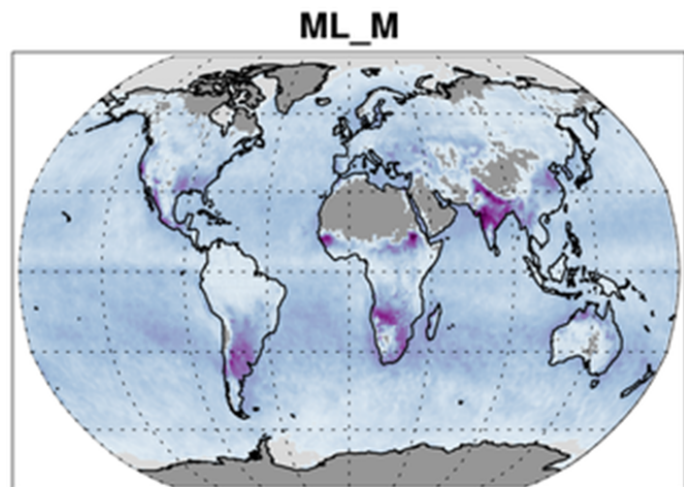

Fraction of pixels with retrieval

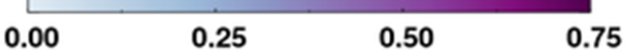

Figure $11.1^{\circ} \times 1^{\circ}$ retrieval fraction provided by the ML_M product during Spring 2013.
Clearly, the retrievability pattern for the V_EDR is least like the ML_M, having the lowest R-squares $\left(R^{2}=0.740\right.$ over ocean and $R^{2}=0.508$ over land). Over ocean, it is both biased negative and has less than one slope. Over land, the overall bias is small, but there is greater scatter. While not apparent when comparing AOD, it is clear from retrievability patterns that the V_EDR algorithm makes different choices than the MODIS algorithm.

\section{5 Ångström Exponent over ocean}

For both the DT and the VIIRS-IDPS algorithms over ocean, the retrieval of AOD at $0.55 \mu \mathrm{m}$ is dependent on exactly matching of the observed and simulated reflectances at $0.86 \mu \mathrm{m}$. We have already analyzed some of the statistics of $0.55 \mu \mathrm{m}$ AOD in the previous sections. Here, we look at the spectral dependence of the 0.55 and $0.86 \mu \mathrm{m} \mathrm{AOD,} \mathrm{in}$ the form of the Angström exponent (AE). AE is defined as $\mathrm{AE}=-\left(\ln \left(\tau_{-} \lambda_{1} / \tau_{-} \lambda_{2}\right) / \ln \left(\lambda_{1} / \lambda_{2}\right)\right)$, where $\tau$ is AOD and $\lambda_{1}, \lambda_{2}$ are the two wavelengths. The AE is inversely related 

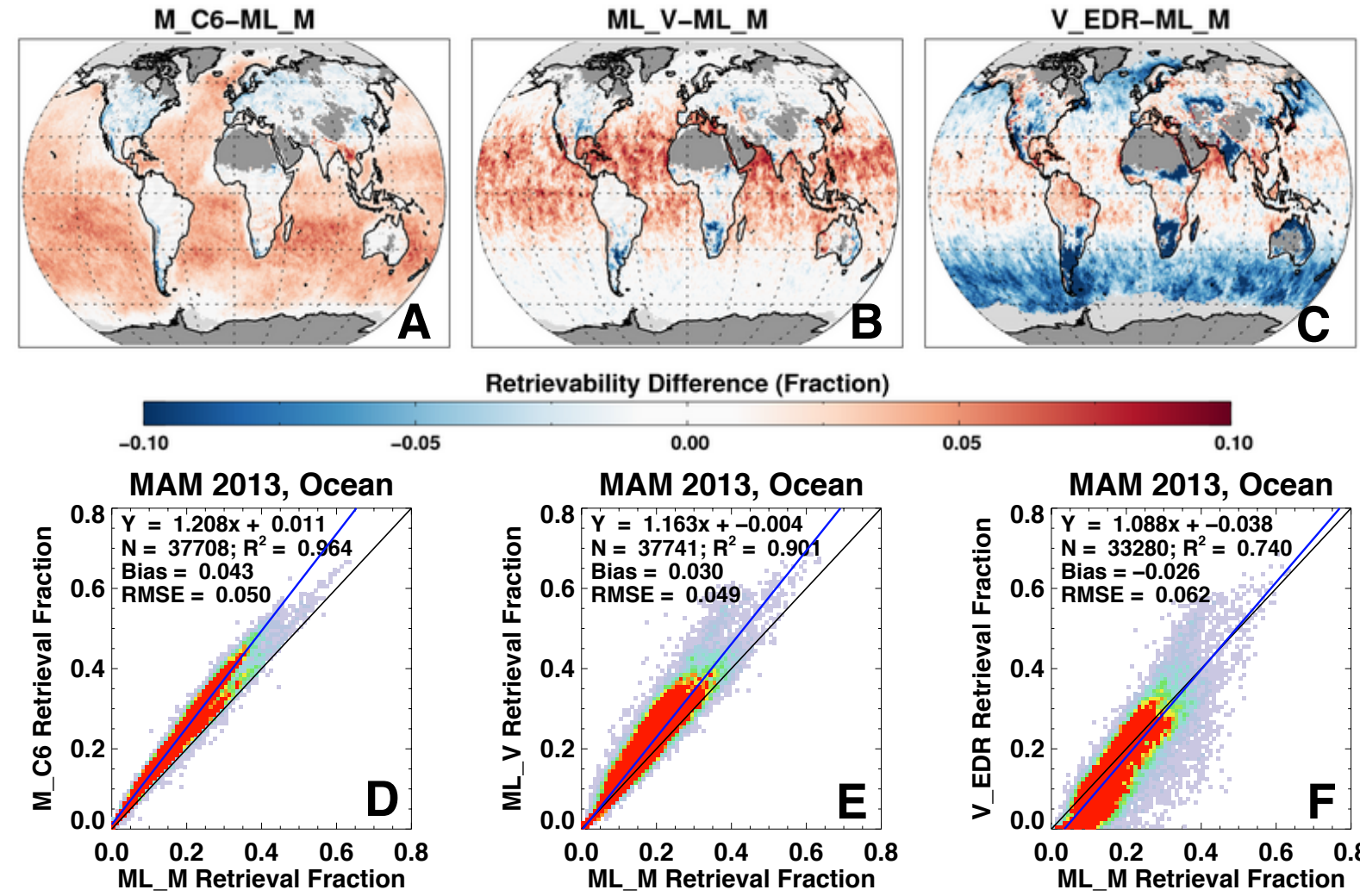

Retrievability Difference (Fraction)
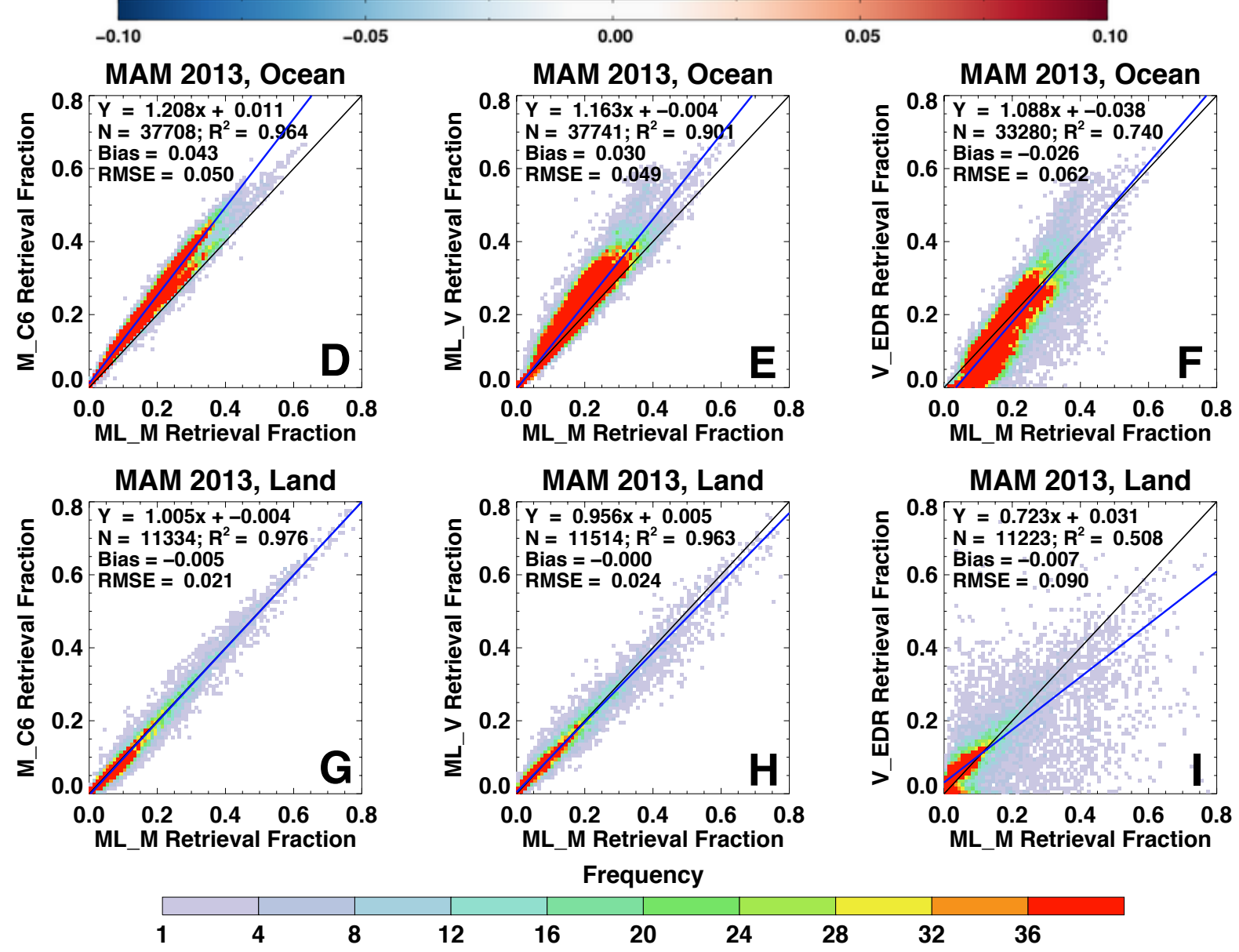

Figure 12. Comparing retrieval fraction between each product and the ML_M product (Fig. 11). The top row (a-c) are difference maps, whereas the bottom two rows (d-f for ocean and $\mathbf{g}-\mathbf{i}$ for land) are frequency scatterplots.

to the general size of the aerosol particles, so that smaller values $(\mathrm{AE}<1.0)$ are associated with large-sized (e.g., dust or sea salt) and larger values $(\mathrm{AE}>1.0)$ are indicative of combustion (pollution or smoke) particles.

Figure 13 presents Spring (MAM) 2013 statistics for the $\mathrm{AE}$ over ocean, computed for each of the different data sets. Maps of AE are calculated by creating separate maps of AOD at $0.55 \mu \mathrm{m}$ (e.g., Figs. 3 and 9) and $0.86 \mu \mathrm{m}$, so that AE can be calculated at each grid box from the means of these two wavelengths. There are no filters for minimum AOD. For the original MODIS C6 data (Fig. 13a), the Saharan dust belt and the sea salt of the southern oceans are clearly marked by $\mathrm{AE}<0.5$. The Asian pollution and US East Coast pollution plumes have $\mathrm{AE}>1.0$. The ML_M map (Fig. 13b) is nearly identical, with $R^{2}=0.935$ and mean bias less than 0.01 . Although the ML_V map is well correlated with the ML_M $\left(R^{2}=0.82\right.$ for collocated grids in Fig. $\left.13 \mathrm{~g}\right)$, and spatial features are similar, its regression is not one-to-one (slope $=0.81$, offset $=0.24$; bias $=0.12$ ). The AE map of the V_EDR, however, does not resemble MODIS or MODIS- 

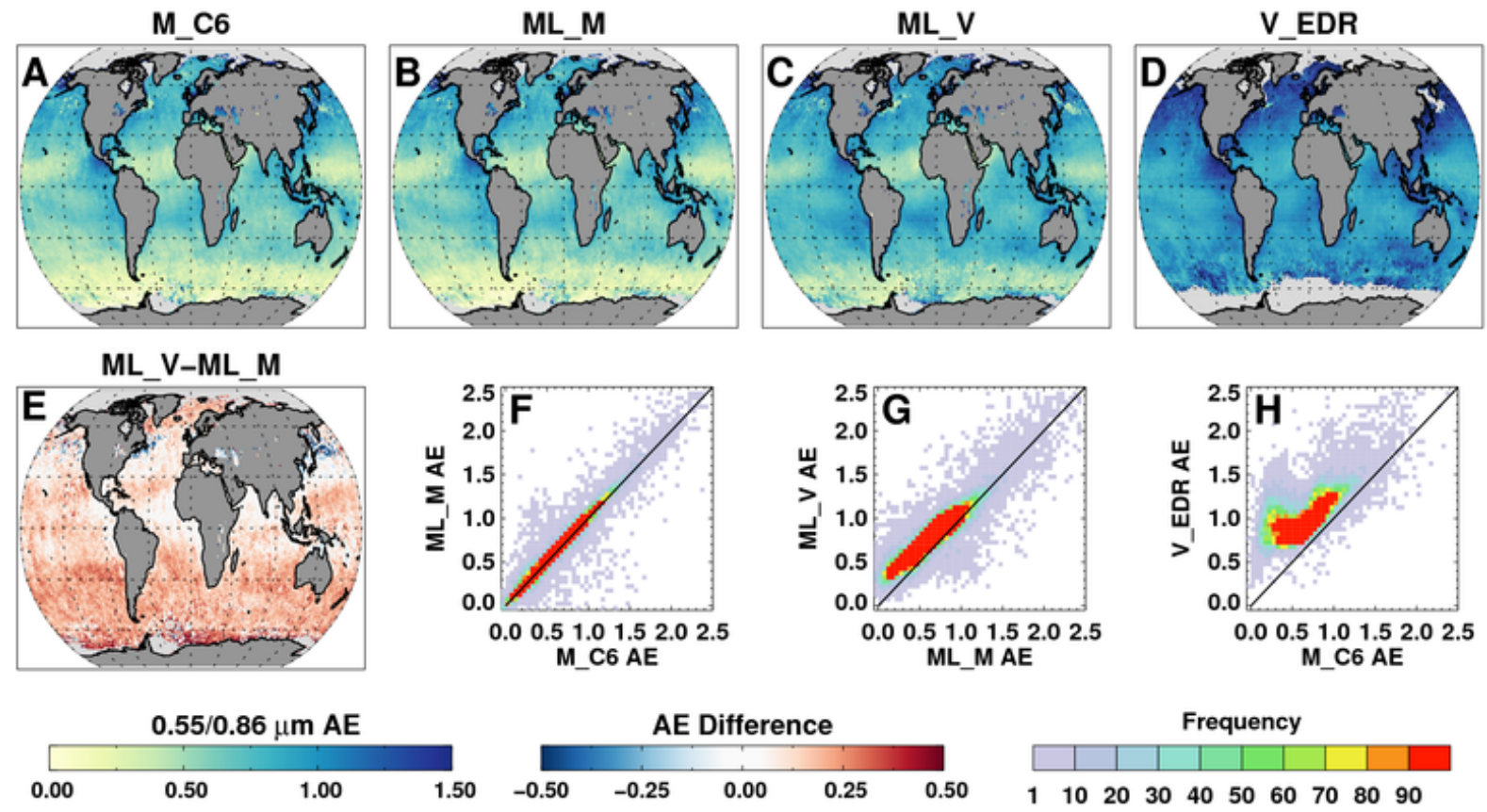

Figure 13. Spring 2013 (March-April-May) maps $\left(1^{\circ} \times 1^{\circ}\right)$ of QA-filtered AE $(0.55 / 0.86 \mu \mathrm{m})$, derived from spectral AOD retrieved from the MODIS Collection 6 (a), MODIS-like algorithm on MODIS (b) and VIIRS (c) IFF, as well as on the V_EDR (d). (e) is the difference between the two ML data sets. (f-h) are scatterplots comparing gridded AE from the different data sets.

like data sets at all. The Southern Ocean and dust AE minima are not seen in the V_EDR map, and the scatterplot (Fig. 13h) shows weak relationship $\left(R^{2}=0.43\right)$, which is both high biased (0.34) and far from one-to-one. It is interesting that one algorithm (the ML_V) is biased in AOD $(0.55 \mu \mathrm{m})$ but reasonable for AE, whereas another (the V_EDR) matches in AOD $(0.55 \mu \mathrm{m})$ but not at all for AE.

\subsection{AOD and AE: comparison with AERONET}

While this paper is not focused on the "validation" of our MODIS-like retrievals, it is useful to compare all four data sets to ground-based AERONET sunphotometer data. Specifically, we have used Level 2 (Version 2) spectral AOD, where quadratic interpolation (in $\log -\log$ space; Eck et al., 1999 ) is used to interpolate to satellite wavelengths (e.g., 0.55 or $0.86 \mu \mathrm{m})$. We used the collocation strategy of Levy et al. (2010), such that $5 \times 5$ boxes ( 25 values) of satelliteretrieved product are compared with AERONET observations within \pm 30 min (usually four or five values) of overpass. A valid collocation is mutually cloud-free, requiring at least two observations for AERONET and five values for the satellite. This means we have neglected any impact of different product resolution (10 vs. 7.5 vs. $6.0 \mathrm{~km}$ ).

We compare M_C6, ML_M, ML_V and V_EDR data sets from an entire year of observations (March 2013February 2014). This year provides a complete annual cycle for validated V_EDR as well as for M_C6. Statistics of the collocations (AOD at $0.55 \mu \mathrm{m}$ and $\mathrm{AE}$ ) are reported as Ta- ble 6, with AOD scatterplots as Fig. 14. Results are compared with the M_C6 expected error (EE) envelopes as suggested by Levy et al. (2013), specifically $(+0.04+10 \% ;-0.02-$ $10 \%)$ over ocean and $\pm(0.05+15 \%)$ over land. For AE, we use EE of \pm 0.4 .

With 1418 collocations over ocean, the M_C6 demonstrates strong relationship $\left(R^{2}=0.88\right)$, near one slope (0.983), but with a small positive bias (0.02). More than $75 \%$ of the points match within EE. The ML_M has $1 \%$ fewer valid collocations (1399) and the statistics are similar. For both MODIS-derived data sets, the mean AOD bias (red dots) increases with AOD for small AOD $(<0.1)$, but is nearly constant for higher AOD. Looking at the V_EDR, it meets EE standards by having more than $69 \%$ of collocations within EE and correlation similar to ML_M. It is slightly higher biased overall $(+0.03)$ than M_C6, but shows a different bias pattern. Instead of increasing with AOD, it is nearly constant. Having a $50 \%$ wider swath, the V_EDR has $\sim 50 \%$ more collocations than does either MODIS data set.

The ML_V data set is high-biased (0.04) as compared to AERONET. The R-squared $\left(R^{2}=0.92\right)$ is stronger than it is with three data sets, but with slope of 1.17 it has only $65 \%$ within EE. Like either M_C6 or ML_M, the ML_V has a bias discontinuity near $\mathrm{AOD}=0.1$ (e.g., Fig. 14c). With $61 \%$ more collocations (2297) than ML_M, this is better than would be expected based on swath alone, reflecting the overall greater retrieval fraction. 

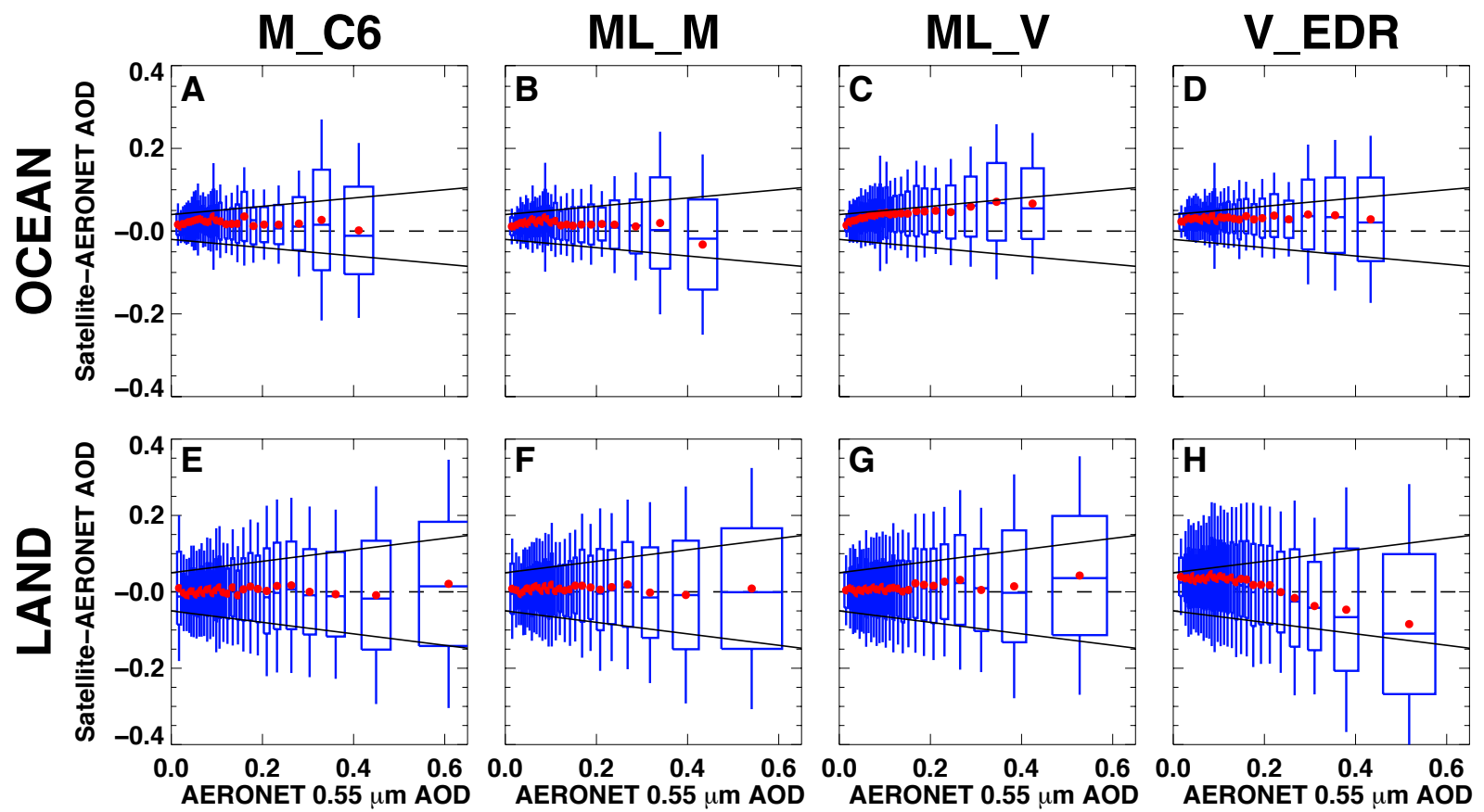

Figure 14. Global satellite-AERONET comparison of AOD at $0.55 \mu \mathrm{m}$, for each of four satellite-derived data sets, for period March $2013-$ February 2014. For each panel, data are sorted by AERONET AOD, so that each box-whisker represents the same number of data points. The blue box and whiskers indicate the median $50 \%$, the middle $66 \%$ and the middle $95 \%$ of the collocations. The red dots represent the mean for the set of collocations. The solid black lines indicate the expected error for MODIS as suggested by Levy et al. (2013), which is $\pm(0.05+15 \%)$ for land, and $(0.04+10 \%$ and $-0.02-10 \%)$ over ocean. Details of the statistics, including linear regression statistics (satellite vs. AERONET) are listed as Table 6.

Looking at $\mathrm{AE}(0.55 / 0.86 \mu \mathrm{m})$ over ocean, even though there are large differences between M_C6 and V_EDR as shown in Fig. 13, when it comes to comparison with AERONET, AE regressions are not as divergent. Since we require that $\mathrm{AOD}>0.20$ (e.g., Levy et al., 2013), $\mathrm{AE}$ is only collocated at $25 \%$ of the AOD pixels. All algorithms provide similar R-squared $\left(R^{2} \sim 0.7\right)$, but have difficulty capturing the dynamic range of AERONET. All four sets have positive $y$ intercepts (ranging from 0.18 to 0.47 ) and less than one slope (ranging from 0.64 to 0.77 ). Interestingly, the best performance comes from the ML_V algorithm. While it has a small negative overall bias, its slope is closest to unity, its $y$ intercept is closest to zero, and its correlation is highest. This means that the ML_V algorithm retrieves the most accurate $\mathrm{AE}$, despite retrieving the least accurate $\mathrm{AOD}$ over ocean.

Over land, Table 6 indicates that all AOD retrievals generally fit within EE envelopes and have overall biases close to zero. Three of the data sets (M_C6, ML_M and ML_V) have slopes between 1.0 and 1.1, offsets having absolute value less than 0.01 , and correlations around $R^{2}=0.81$. The V_EDR performs less well, having slope (0.77), intercept (0.029) and correlation $\left(R^{2}=0.68\right)$. Thus, the performance of the ML_V over land is much more consistent with either MODIS-derived data set, than is the V_EDR. It is interesting that the V_EDR has nearly $80 \%$ more AERONET matches as compared to ML_M, whereas the ML_V only has $25 \%$ more. The $25 \%$ increase is primarily due to the increase in swath width, with the additional collocations a result of different algorithm (and retrievability) of the V_EDR.

\section{Global time series}

In the previous sections we compared the different data sets using global statistics from the 3-month MAM 2013 period and evaluation using a 1 -year period. While interesting for algorithm development, this does not begin to assess the long-term data continuity aspect. It is possible that the offsets, say for ML_V compared to ML_M, do not continue for other seasons or across multiple years. Using the computing power of the A-SIPS, we performed the MODISlike retrieval on all overlapping MODIS and VIIRS observations from April 2012 through May 2014 (slightly more than two complete years). Figure 15 presents the time series of monthly global $0.55 \mu \mathrm{m}$ AOD, as computed via equal grid weighting from each of the four data sets. The top plots are the AOD over land and ocean, and the bottom two are the differences, as compared to the ML_M. Due to processing error, there is missing V_EDR in late 2012. The green ar- 
Table 6. Validation of QA-filtered AOD and AE at $0.55 \mu \mathrm{m}$, compared to collocated ground-based AERONET observations, for the period March 2013-February 2014. EE for AOD is $(+0.04+10 \% ;-0.02-10 \%)$ over ocean and $\pm(0.05+15 \%)$ over land. EE for AE as \pm 0.4 , and requires that satellite-retrieved AOD $>0.20$. Statistics are for linear regression of the $N$ points.

\begin{tabular}{llrrrrrrrrr}
\hline Product & Land or Ocean & $N$ & \% within EE & \% above EE & \% below EE & Bias & RMSE & Slope & $y$ int & $R^{2}$ \\
\hline M_C6 & Ocean & 1418 & 75.95 & 18.96 & 5.36 & 0.024 & 0.073 & 0.983 & 0.020 & 0.884 \\
ML_M & Ocean & 1399 & 77.27 & 17.01 & 5.72 & 0.021 & 0.070 & 0.986 & 0.018 & 0.896 \\
ML_V & Ocean & 2297 & 65.74 & 32.30 & 1.96 & 0.044 & 0.082 & 1.170 & 0.015 & 0.915 \\
V_EDR & Ocean & 2139 & 69.47 & 26.32 & 4.21 & 0.033 & 0.064 & 1.040 & 0.024 & 0.887 \\
\hline M_C6 & Ocean AE & 289 & 77.16 & 10.73 & 12.11 & 0.01 & 0.319 & 0.665 & 0.323 & 0.688 \\
ML_M & Ocean AE & 290 & 80.34 & 9.31 & 10.34 & 0.014 & 0.309 & 0.693 & 0.306 & 0.714 \\
ML_V & Ocean AE & 504 & 85.52 & 6.75 & 7.74 & 0.023 & 0.286 & 0.768 & 0.176 & 0.747 \\
V_EDR & Ocean AE & 489 & 77.51 & 16.56 & 5.93 & 0.129 & 0.35 & 0.639 & 0.473 & 0.678 \\
\hline M_C6 & Land & 3801 & 68.17 & 17.26 & 14.60 & 0.004 & 0.105 & 1.007 & -0.008 & 0.818 \\
ML_M & Land & 4128 & 68.12 & 19.84 & 12.04 & 0.012 & 0.101 & 1.003 & 0.003 & 0.812 \\
ML_V & Land & 4989 & 65.44 & 17.52 & 17.04 & 0.005 & 0.111 & 1.011 & -0.007 & 0.816 \\
V_EDR & Land & 7358 & 67.67 & 20.56 & 11.77 & 0.007 & 0.121 & 0.776 & 0.029 & 0.683 \\
\hline
\end{tabular}
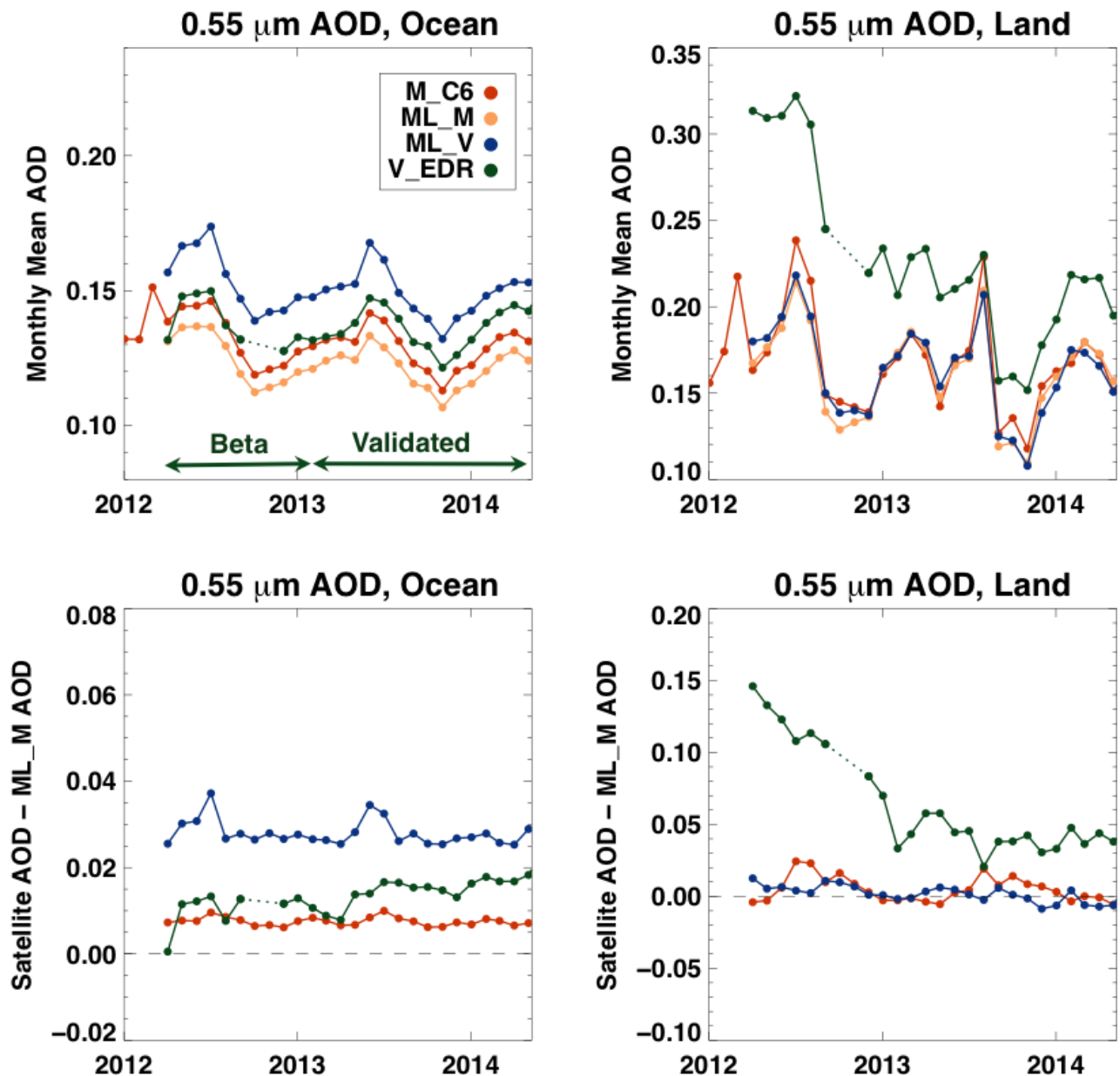

Figure 15. Time series of monthly mean, global AOD at $0.55 \mu \mathrm{m}$, over ocean (left panels) and land (right panels). The top panels refer to the magnitude, the bottom plots are the differences as compared to the MODIS-like on MODIS. The "beta" and "validated" refers to the VIIRS EDR product, highlighting the relative convergence of VIIRS EDR for global mean, after February 2013. Note different $y$ scales. 
rows on Fig. 15a denote the relative periods of "beta" quality and "validated stage 2" quality V_EDR data.

Over ocean, all time series show the same seasonal cycle (Fig. 15a). Highest AOD is observed during the May/June months, with lowest during the October/November months. An average $\sim 0.008$ offset between M_C6 and ML_M is apparent for all months, with little variability over time. An average $\sim 0.012$ offset between V_EDR and ML_M is apparent, but it apparently increases over time. In fact, the offset after February 2013 continues to increase, approaching 0.02 by 2014. The pattern of the ML_V compared to ML_M is interesting. While the $\sim 0.025$ offset does not change from year to year, the offset is even larger (more than 0.035) during the late spring maximums. This represents the combination of extra retrieval fraction and enhanced AOD observed during the late spring aerosol transports (from Asia and Africa).

Over land, there is also a seasonal cycle observed (Fig. 15b) by both ML_M and M_C6, but there are two humps (Northern Hemisphere early winter and late spring), along with much more variability. There are minima in October of both years, with 2013 lower than 2012. Although we saw nearly identical AOD for the MAM 2013 period (Table 5), the offset between ML_M and M_C6 actually varies with season, ranging from near zero to as large as 0.02 during the late spring and through the summers. Interestingly, the variability of ML_V compared to ML_M is less than M_C6 compared to ML_M. Finally, while the V_EDR settles down towards the ML_M after February 2013 (validated stage 2$)$, the monthly offsets remain large $(\sim 0.03)$ and variable $( \pm 0.02)$.

\section{Discussion}

In the previous sections, we first compared the V_EDR data product with M_C6. Then, we created a simplified MODISlike algorithm that was run on the MODIS-IFF data (ML_M) and VIIRS-IFF data (ML_V). Based on the figures and statistics, we saw the following.

- The $0.55 \mu \mathrm{m}$ AOD from V_EDR over ocean is similar to M_C6. Global mean AOD is within \pm 0.01 of M_C6. While V_EDR has significantly more coverage, overall retrieval fraction is smaller. For common $1^{\circ} \times 1^{\circ}$ grids, AOD relationship is strong $\left(R^{2}=0.89\right)$ and regression is near one-to-one. Compared to AERONET, the V_EDR and M_C6 both meet expected error requirements. The V_EDR has fewer retrievals of small $\mathrm{AOD}<0.02$.

- Over-ocean AE $(0.55 / 0.86 \mu \mathrm{m})$ retrieved from V_EDR is offset high and has weak relationship to M_C6 $\left(R^{2}=\right.$ $0.43)$.

- Over land, the V_EDR has positive offset and provides different spatial coverage of AOD. The V_EDR does not retrieve negative AOD. $R^{2}<0.58$, slope is 0.68 and offset is 0.10 . AERONET collocation confirms that the V_EDR is too high at low AOD and too low at high AOD.

- Primarily due to cloud and surface masking, the ML_M data set is not exactly M_C6. There is almost no difference in overall Level 2 statistics or difference when comparing with AERONET; however, the retrieval fraction is lower over ocean and greater over land, which creates differences when gridded into Level 3. There is negligible difference in gridded $\mathrm{AE}$ over ocean.

- Over ocean, the ML_V AOD is strongly related to ML_M $\left(R^{2}=0.86\right)$ but is biased high by about $20 \%$ in both L2 and L3 statistics. Retrievability is correlated spatially, but there is $15 \%$ larger retrieval fraction with the ML_V product. These biases are confirmed with AERONET collocations. AE is also spatially correlated, and when comparing to AERONET, AE from the ML_V is better than ML_M.

- Over land, the ML_V looks much like ML_M. Regressions compared to AERONET are nearly identical, and spatial correlation between ML_V and ML_M maps is high $\left(R^{2}=0.92\right)$. Global retrievability and mean AOD are nearly identical.

- The ML_V provides a more MODIS-like picture than did the V_EDR, especially over land.

Assessing two or more global aerosol data sets is complicated. Comparing each with AERONET (e.g., validation) provides some information. Comparing Level 2 pixel histograms and Level 3 gridded maps and global coverage provides more. To connect the Level 2 results with the Level 3 results, we compared global retrievability statistics. Whether an algorithm "chooses" to retrieve or not to retrieve for specific cases impacts the aggregated result. Retrievability statistics help to interpret apparently contradicting statistics, such as over-land data AOD being biased low in some metric (e.g., Level 2 means and histograms), but not when compared to others (e.g., global AERONET data and Level 3 means).

When a common algorithm is applied to different sensors, differences in the aerosol products can be reduced but not eliminated. Clearly, there are still issues related to differences in the MODIS and VIIRS sensors that impact how a common algorithm will perform. For the remainder of this section, we hypothesize some of the causes for biases and retrievability differences. In the end, to create the most seamless CDR, some algorithmic changes may be required to accommodate the differences between the sensors.

\subsection{Pixel spatial resolution issues}

The spatial resolution of the input reflectances for the four algorithms varies, with M_C6 and V_EDR using a mix 
of higher resolution $(0.25$ and $0.5 \mathrm{~km}$ for M_C6, $0.375 \mathrm{~km}$ for V_EDR) and lower resolution bands (1 km for M_C6, $0.75 \mathrm{~km}$ for $\mathrm{V} \_$EDR). The IFF input reflectance files used for the ML_M and ML_V files have only the lowest resolution bands for each sensor. The changes in reflectance pixel resolution primarily affect three main parts of the algorithm:

- cloud masking,

- surface feature masking,

- retrieval QA assignment.

The MODIS-like algorithm has a less precise cloud mask than standard M_C6. Primarily this is due to spatial resolution. For example, in the standard MODIS aerosol cloud mask, operating on $0.5 \mathrm{~km}$ resolution pixels, the algorithm will mask any pixel exceeding a reflectance threshold. It will also mask the center pixel for a set of $3 \times 3$ pixels that exceeds a spatial variability threshold. The surviving pixels will likely have a lower mean reflectance than if the masked pixel was included. If the combination of the masked pixel and surrounding pixels are equivalent to a single lower resolution (i.e., $1 \mathrm{~km}$ pixel), then the mean or variability may not exceed thresholds. If the masking was performed at $1 \mathrm{~km}$ resolution (e.g., the ML_M), a blurred scene may survive, and lead to cloud contamination. On the other hand, the cloud pixel may be bright enough to lead to high enough reflectance in the entire $1 \mathrm{~km}$ area, leading to clear sky bias. Over ocean, the lower-resolution ML_M algorithm is tending to throw away a larger portion of a $10 \mathrm{~km}$ aerosol retrieval box than the standard M_C6, leading to lower retrievability, and a clear sky bias to the retrieval. The resulting AOD is smaller.

Over land, the differences between ML_M and M_C6 are more likely due to resolution of surface feature masks. Although both use the same water fraction database (e.g., Carroll et al., 2009), additional small and ephemeral inland water bodies (rivers, ponds, etc.) are identified by low values of NDVI. Retrieval fraction will generally be increased with this blurred surface, and the retrieved AOD will generally be higher, especially for clean cases. This is because surface reflectance ratios for murky inland water do not match assumptions. Visible reflectance is proportionally much higher than the very dark mid-infrared reflectance of water, and the unexpected higher reflectance in the visible is mistakenly attributed to aerosol in the retrieval. The same issues come up for subpixel snow and for other feature masks.

Although both ML_M and M_C6 products are $10 \mathrm{~km}$ retrievals, we are reminded (e.g., Sect. 3.3) that in addition to masking, the different pixel resolutions ( 1 vs. $0.5 \mathrm{~km}$ ) lead to different pixel aggregations. Whereas there are 400 possible pixels in M_C6, there are only 100 for ML_M. Even if cloud or surface masking was applied identically, the sorting protocols (e.g., $25-75 \%$ over ocean or $20-50 \%$ over land) will result in different mean spectral reflectance to perform the aerosol retrieval (i.e., the spectral inversion). Furthermore, since the final pixel thresholds associated with higher confidence are not integer fractions of those used for M_C6, it may be more or less difficult to receive the required QAC level. Over land, the fraction of valid data is lower for ML_M than M_C6, but the final number receiving sufficiently high $\mathrm{QAC}$ is larger.

In regards to differences between $M L \_V$ and $M L \_M$, the use of $750 \mathrm{~m}$ vs. $1 \mathrm{~km}$ pixels should affect cloud and surface masking. There is qualitative similarity between the middle and left-hand panels of Fig. 12, suggesting that the higher resolution of ML_V is having a similar effect as using a better resolution MODIS product.

\subsection{Wavelength issues}

Unlike ML_M and M_C6 that both use MODIS-Aqua observations as input, differences in AOD and retrievability between ML_V and ML_M may partially be caused by wavelength shifts. While we have designed the ML_V algorithm to account for wavelength-specific clear-sky atmospheric effects (aerosol, Rayleigh and gas contributions), we have less control over surface boundary and masking conditions.

Figure 5 showed that for a typical vegetated surface, the surface reflectance is larger at $0.49 \mu \mathrm{m}$ (used by VIIRS) than at $0.47 \mu \mathrm{m}$ (used by MODIS), and smaller at $0.67 \mu \mathrm{m}$ (used by VIIRS) than at $0.65 \mu \mathrm{m}$ (used by MODIS). In the global mean, and for most regions, adopting the VIIRS-IDPS surface relationships (Liu et al., 2014) appears to work well. However, a full atmospheric correction exercise (e.g., Levy et al., 2007a) could determine surface reflectance relationships for VIIRS that are more analogous to MODIS.

In addition, shifted wavelengths will impact thresholds required for cloud and surface masking. For example, over land, the MODIS algorithm masks clouds based on reflectance and spatial variability of reflectance in the blue channel. If the surface reflectance is already larger at $0.49 \mu \mathrm{m}$ (VIIRS) than at $0.47 \mu \mathrm{m}$ (MODIS), it may be more likely to exceed a MODIS-based cloud mask threshold. Similar arguments hold for other channels used for other masks, but systematic study is beyond our scope here.

\subsection{Calibration}

Finally, there is the issue of calibration. The MODIS instruments were calibrated to laboratory standards more than 15 years ago. The degradation of MODIS VIS/NIR/SWIR bands on Terra has been generally more severe (e.g., Lyapustin et al., 2014 and references therein), but MODIS on Aqua has also experienced degradation and calibration anomalies. Since the original radiometric calibrations were required to be within $\pm 2 \%$ (for typical values), and subsequent updates were made relative to the original, the uncertainties remain or can become larger over time. Even for MODIS Collection 6 (e.g., Levy et al., 2013), we will likely see that global AOD derived from Terra has a systematic 
+0.015 offset as compared to Aqua. Using the results reported by Lyapustin et al. (2014) in cross-calibrating Terra to Aqua observations, we performed an offline test and confirmed that Terra/Aqua differences could be reduced. Although it is not yet proven that Terra is more "biased" than Aqua, we tend to assume that aerosol climatology should normalize towards Aqua.

VIIRS on S-NPP was lab-calibrated as recently as 2011. Like MODIS, VIIRS radiometric calibration is also expected to have uncertainty on the order of $\pm 2 \%$ (e.g., Cao et al., 2014). Thus, it is not unreasonable to believe that the two instruments could be different by more than $\pm 2 \%$, and might vary by wavelength band. Theoretically, where both sensors observe the same scene, with the same geometry, and at the same time (known as a simultaneous nadir overpass or SNO), then one can compare them directly. However, even though both MODIS and VIIRS have ascending orbits that cross the equator at 13:30 local solar time, their only true overlap is for a few minutes every few days, and only poleward of $70^{\circ}$ (north or south). SNOs over ice or snow or clouds do not provide sufficient insight into darker surfaces, so we also need to look at "near" SNOs, which, depending on tolerances (time, spatial and angular differences) can occur in low-latitudes. Since near-SNOs do not have the exact same time or geometry, issues including moving clouds and surface bi-directional radiance function (BRDF) will have to be accounted for. In addition, with the problem of wavelength shift, observed TOA reflectance will not be identical (spectral dependence of Rayleigh optical depth, surface reflectance, gas absorptions, etc.) even under the exact same geometry. Therefore, calibration biases have to be separated from apparent biases, using sophisticated radiative transfer convolved with spectral libraries.

In this direction, Uprety et al. (2013) and others have compared MODIS-Aqua and VIIRS over near-SNOs located in the tropics and mid-latitudes. Although not all DT bands have been compared consistently, the general conclusion was that at least some of the VIIRS bands appear to be biased high as compared to MODIS. The Uprety et al. (2013) study indicated that the VIIRS M4 $(0.55 \mu \mathrm{m})$, M5 $(0.67 \mu \mathrm{m}), \mathrm{M} 7$ $(0.86 \mu \mathrm{m})$ and M8 $(1.24 \mu \mathrm{m})$ bands had residual high biases of 1.6, 1.3, 2.2 and $3.5 \%$, respectively, (with error bars of $1-2 \%$ ). Based on personal communication, S. Uprety (2014) suggested that the M11 band $(2.26 \mu \mathrm{m})$ also appears to have a high bias, but more study was required.

With such large uncertainties to VIIRS vs. MODIS calibration biases, we are not yet at a stage where a particular set of coefficients can be applied to make VIIRS agree with MODIS. Additionally, there are additional issues, similar to those described by Lyapustin et al. (2014) for MODIS, that include view angle dependence, polarization, and other corrections. Nonetheless, when we apply the inverse of Uprety et al.'s (2013) mean factors to archived VIIRS-IFF data, we see the global over-ocean mean AOD decrease by 0.01 (half of the $\sim 0.02$ bias). Over land, although no change for global
AOD, we saw regional changes. Note, however, that since we did not also scale M3 $(0.49 \mu \mathrm{m}), \mathrm{M} 10(1.60 \mu \mathrm{m})$ or M11 $(2.26 \mu \mathrm{m})$ channels (no published factors), it is likely that resulting AOD and AE retrievals will be inconsistent. Regardless, the upshot is that calibration matters, and applying correction factors of $\pm 2 \%$ to selected channels can make VIIRS converge towards MODIS. For climate continuity, the recalibration must be carefully applied (e.g., Turpie et al., 2012).

\section{Summary/conclusion}

Since early 2000, NASA's MODIS sensors have been applying the "dark-target" (DT) aerosol algorithms to characterize AOD at $0.55 \mu \mathrm{m}$ over land and ocean, and AE over ocean. With the near completion of a re-processed data set known as M_C6, MODIS products continue to be integral to both routine and research applications. As we move toward the JPSS era, VIIRS on Suomi-NPP is intended to provide a bridge for continuing an aerosol data record, and ensuring continuity for climate applications. As of early 2015, VIIRS has been flying concurrently with MODIS for over 3 years.

Although MODIS and VIIRS have similar capabilities, and the aerosol retrieval algorithms have similar heritage, there are many differences between the operational VIIRSEDR and MODIS-C6 aerosol products. The instruments have different orbits, different ground sampling, spatial resolution and wavelength bands. The aerosol algorithms use different masking (clouds and surfaces) techniques, along with different strategies for pixel aggregation and retrieval. The aerosol products have different formats and cater toward different research communities. While the V_EDR aerosol products have similar global uncertainties as compared to M_C6, the differences can be large, especially over land.

In this work, we have applied a MODIS-like DT algorithm on VIIRS. We used the MODIS RT assumptions to create aerosol lookup tables that account for shifted wavelength bands. We applied MODIS-like surface and cloud masking and MODIS-like pixel aggregation. To test our algorithm, we relied on the IFF data produced by the Atmosphere SIPS at University of Wisconsin. Since IFF was produced for both MODIS and VIIRS, we used the same MODISlike algorithm to produce ML_M and ML_V for the period March 2012-May 2014. We focused on the 3-month period covering March-May 2013. ML_V and ML_M were compared with each other as well as with M_C6 and V_EDR.

At the same time as comparing ML_V with ML_M, we characterized the differences between ML_M and M_C6. Since the ML_M is based on degraded input pixel resolution $(1 \mathrm{~km}$ vs. $0.5 \mathrm{~km})$ and no thermal IR data, there were some small impacts to cloud masking (especially over ocean), and surface masking (especially over land). In addition, the difference in input pixel resolution impacted the detection and masking of ephemeral and inland waters. The result was that while there was very little change to global AOD statistics 
(Level 2 histograms), there were changes to some $1^{\circ} \times 1^{\circ}$ grids, which affected a Level 3 global mean. The retrieval fraction and concept of retrievability was investigated.

In general, the ML_V was much more similar to ML_M than the V_EDR was to the M_C6. It did not matter whether using the entire swath width or subsetting to a MODISsized width $\left(\mathrm{VZA}<60^{\circ}\right)$. Over land, global mean AOD and global retrieval fractions were almost identical. Regionally, there were both high and low biases, but when regressed as a scatterplot, most grids fell near the one-to-one line $\left(R^{2}=\right.$ $0.935)$. Retrieval fractions were nearly identical globally, and gridded values regressed nearly one-to-one on a scatterplot $\left(R^{2}=0.963\right)$. Both ML_V and ML_M provided similar performance when comparing retrieved AOD to AERONET observations. In fact, even with non-tuned surface reflectance relationships, the ML_V and the ML_M appear to view global dark land with the same eyes.

On the other hand, the ML_V is biased compared to MODIS over ocean. ML_V global ocean $0.55 \mu \mathrm{m}$ AOD is greater by 0.02 or nearly $20 \%$, and global scatterplots and maps show that the $20 \%$ bias is everywhere. Some of that bias may be due to differences in cloud masking under a different resolution pixel regime $(0.75 \mathrm{vs} .0 .5 \mathrm{~km})$, but then the zonal differences in retrieval fractions do not necessarily support this. Interestingly, while the global green wavelength AOD is biased high by $20 \%$, the bias at longer wavelengths is smaller. In fact the ML_V view of $0.55 / 0.86 \mathrm{AE}$ is biased high compared to a MODIS view, indicating stronger spectral dependence, and tends to have better correlation to AERONET observations. A 1-2\% correction to VIIRS reflectance data may make VIIRS spectral dependence and retrieved $0.55 \mu \mathrm{m}$ AOD look more like MODIS over the ocean, but the uncertainties still need to be explored. Plus, without applying consistent corrections to all wavelengths, one may introduce new biases to the over-land retrieval, to other VIIRS products, or to "downstream" products that might use the aerosol products (e.g., Loeb et al., 2006).

The MODIS-like algorithm on VIIRS data yields results that are more consistent with MODIS (C6) data. However, the overlap is not perfect. Most likely some of the differences are due to calibration. However, we still seek a better characterization of differences that will arise from pixel resolution and its impacts on masking and surface identification. Our intention is to not only stitch together products of total AOD (at $0.55 \mu \mathrm{m}$ ), but also aerosol size and spectral dependence, which may prove to be the more difficult task.

Climate science requires long continuous data set time series. Average aerosol optical depth (AOD) over the globe is on the order of 0.15 , and modeled global trends over the last few decades are at most 0.01 per decade. Thus to discern a global aerosol trend we will require continuity to better than 0.01 . We have shown that this value is difficult to reach, even using the same sensor and the same algorithm but at different resolutions. Conversely, we have also shown that continuity of 0.01 should be possible as we cross from MODIS to VIIRS, if the difficulties of sensor characterization in all its forms are well-understood and addressed. At this point, we have processed limited data from both MODIS and VIIRS. We have relied on the IFF data provided by the A-SIPS, which excludes information (higher spatial resolution bands, thermal IR bands, cloud mask) that should be included in a future version of a MODIS-like algorithm for VIIRS. Omitting this information hinders a MODIS-like algorithm from duplicating the long-term MODIS algorithm results. Incomplete calibration verification for all VIIRS channels is another road-block. There are still many steps to take before we can achieve a true MODIS $\rightarrow$ VIIRS aerosol continuity, using the full suite of spectral and spatial information provided by both sensors. Clearly, our work is not done.

Fortunately, MODIS and VIIRS are both currently flying, and are both in nominal operational states. At this point, there are more than 3 years of overlapping observations, which we hope will be extended as long as possible. As we continue to develop a more consistent algorithm between MODIS and VIIRS, and to monitor calibration on each sensor, we will use the overlapping time series as a test bed and to prepare for a time when VIIRS is flying alone. By that time we expect the two data sets to converge even closer and provide the necessary continuity in aerosol properties.

Acknowledgements. We thank the Wisconsin-PEATE (now SIPS) team for their efforts in creating IFF data and managing the creation of the MODIS-like products. Evaluation of these different satellite-retrieved aerosol data sets would not have been possible without AERONET and its team of site managers, for which we are extremely grateful. This research began under the NASA program NNH10ZDA001N-NPP (NPP Science Team for Climate Data Records) and continues under NNH13ZDA001N-SNPP (Suomi National Polar-orbiting Partnership (NPP) Science Team).

Edited by: A. Sayer

\section{References}

Ahmad, Z. and Fraser, R. S.: An iterative radiative transfer code for ocean-atmosphere systems, J. Atmos. Sci., 39, 656-665, doi:10.1175/1520-0469(1982)039<0656:AIRTCF>2.0.CO;2, 1982.

Blonski, S., Cao, C., Shao, X., and Uprety, S.: VIIRS reflective solar bands calibration changes and potential impacts on ocean color applications, in Proc. SPIE, 9111, Ocean Sensing and Monitoring VI, Baltimore, MD, USA, 6-7 May 2014, 911106, 2014.

Bojinski, S., Verstraete, M., Peterson, T. C., Richter, C., Simmons, A., and Zemp, M.: The concept of essential climate variables in support of climatic research, applications, and policy, B. Am. Meteorol. Soc., 95, 1431-1443, doi:10.1175/BAMS-D-13$00047.1,2014$.

Cao, C., Xiong, J., Blonski, S., Liu, Q., Uprety, S., Shao, X., Bai, Y., and Weng, F.: Suomi NPP VIIRS sensor data record verification, validation, and long-term performance monitoring, J. Geophys. 
Res.-Atmos., 118, 11664-11678, doi:10.1002/2013JD020418, 2013.

Cao, C., De Luccia, F. J., Xiong, X., Wolfe, R., and Weng, F.: Early on-orbit performance of the visible infrared imaging radiometer suite onboard the Suomi National Polar-Orbiting Partnership (S-NPP) satellite, IEEE T. Geosci. Remote, 52, 11421156, doi:10.1109/TGRS.2013.2247768, 2014.

Carroll, M. L., Townshend, J. R., DiMiceli, C. M., Noojipady, P., and Sohlberg, R. A.: A new global raster water mask at $250 \mathrm{~m}$ resolution, Int. J. Digit. Earth, 2, 291-308, doi:10.1080/17538940902951401, 2009.

Chan, P. K., Zhao, X. P., and Heidinger, A. K.: Long-term aerosol climate data record derived from operational AVHRR satellite observations, Dataset Papers in Geosciences, 1-5, doi:10.7167/2013/140791/dataset, 2013.

Chin, M., Diehl, T., Tan, Q., Prospero, J. M., Kahn, R. A., Remer, L. A., Yu, H., Sayer, A. M., Bian, H., Geogdzhayev, I. V., Holben, B. N., Howell, S. G., Huebert, B. J., Hsu, N. C., Kim, D., Kucsera, T. L., Levy, R. C., Mishchenko, M. I., Pan, X., Quinn, P. K., Schuster, G. L., Streets, D. G., Strode, S. A., Torres, O., and Zhao, X.-P.: Multi-decadal aerosol variations from 1980 to 2009: a perspective from observations and a global model, Atmos. Chem. Phys., 14, 3657-3690, doi:10.5194/acp14-3657-2014, 2014.

Clough, S. A., Iacono, M. J., and Moncet, J.-L.: Line-by-Line calculations of atmospheric fluxes and cooling rates: application to water vapor, J. Geophys. Res.-Atmos., 97, 15761, doi:10.1029/92JD01419, 1992.

Clough, S. A., Shephard, M. W., Mlawer, E. J., Delamere, J. S., Iacono, M. J., Cady-Pereira, K., Boukabara, S., and Brown, P. D.: Atmospheric radiative transfer modeling: a summary of the AER codes, J. Quant. Spectrosc. Ra., 91, 233-244, doi:10.1016/j.jqsrt.2004.05.058, 2005.

Colarco, P. R., Kahn, R. A., Remer, L. A., and Levy, R. C.: Impact of satellite viewing-swath width on global and regional aerosol optical thickness statistics and trends, Atmos. Meas. Tech., 7, 2313-2335, doi:10.5194/amt-7-2313-2014, 2014.

Cox, C. and Munk, W.: Measurement of the roughness of the sea surface from photographs of the sun's glitter, J. Opt. Soc. Am., 44, 838-850, doi:10.1364/JOSA.44.000838, 1954.

Evans, K. F. and Stephens, G. L.: A new polarized atmospheric radiative transfer model, J. Quant. Spectrosc. Ra., 46, 413-423, 1991.

Franz, B. A., Werdell, P. J., Meister, G., Bailey, S. W., Eplee, R. E. J., Feldman, G. C., Kwiatkowskaa, E., McClain, C. R., Patt, F. S., and Thomas, D.: The continuity of ocean color measurements from SeaWiFS to MODIS, in: Proc. SPIE, 5882, Earth Observing Systems X, San Diego, CA, USA 31 July 2005, 58820W, 304-316, doi:10.1117/12.620069, 2005.

Franz, B. A., Bailey, S. W., and Meister, G.: Quality and consistency of the NASA ocean color data record, Proc. Ocean Optics XXI, 2012.

Frey, R. A., Ackerman, S. A., Liu, Y., Strabala, K. I., Zhang, H., Key, J. R., and Wang, X.: Cloud detection with MODIS, Part I: improvements in the MODIS cloud mask for collection 5, J. Atmos. Ocean. Tech., 25, 1057, doi:10.1175/2008JTECHA1052.1, 2008.
GCOS: Systematic observation requirements for satellite-based products for climate, 2011 update, WMO GCOS Rep. 154, New York, USA, 127 pp., 2011.

Holben, B. N., Eck, T. F., Slutsker, I., Tanré, D., Buis, J. P., Setzer, A., Vermote, E., Reagan, J. A., Kaufman, Y. J., Nakajima, T., Lavenu, F., Jankowiak, I., and Smirnov, A.: AERONET - a federated instrument network and data archive for aerosol characterization, Remote Sens. Environ., 66, 1-16, doi:10.1016/S00344257(98)00031-5, 1998.

Hollmann, R., Merchant, C. J., Saunders, R., Downy, C., Buchwitz, M., Cazenave, A., Chuvieco, E., Defourny, P., de Leeuw, G., Forsberg, R., Holzer-Popp, T., Paul, F., Sandven, S., Sathyendranath, S., van Roozendael, M., and Wagner, W.: The ESA Climate Change Initiative: satellite data records for essential climate variables, B. Am. Meteorol. Soc., 94, 1541-1552, doi:10.1175/BAMS-D-11-00254.1, 2013.

Hsu, N. C., Gautam, R., Sayer, A. M., Bettenhausen, C., Li, C., Jeong, M. J., Tsay, S.-C., and Holben, B. N.: Global and regional trends of aerosol optical depth over land and ocean using SeaWiFS measurements from 1997 to 2010, Atmos. Chem. Phys., 12, 8037-8053, doi:10.5194/acp-12-8037-2012, 2012.

Hsu, C., Levy, R. C., Sayer, A. M., Lee, J., Laszlo, I., Bettenhausen, C., Gautam, R., Mattoo, S., Munchak, L. A., and Liu, H.: Suomi NPP VIIRS Aerosol Data Product Assessment Report, NASA, Washington D.C., USA, 77 pp., 2013a.

Hsu, N. C., Jeong, M. J., Bettenhausen, C., Sayer, A. M., Hansell, R., Seftor, C. S., Huang, J., and Tsay, S. C.: Enhanced deep blue aerosol retrieval algorithm: the second generation, J. Geophys. Res.-Atmos., 118, 9296-9315, doi:10.1002/jgrd.50712, 2013b.

Hyer, E. J., Reid, J. S., and Zhang, J.: An over-land aerosol optical depth data set for data assimilation by filtering, correction, and aggregation of MODIS Collection 5 optical depth retrievals, Atmos. Meas. Tech., 4, 379-408, doi:10.5194/amt-4-379-2011, 2011.

IPCC: Working Group I Contribution to the IPCC Fifth Assessment Report (AR5), Climate Change 2013: The Physical Science Basis, Intergovernmental Panel on Climate Change, Geneva, Switzerland, 2013.

Jackson, J. M., Liu, H., Laszlo, I., Kondragunta, S., Remer, L. A., Huang, J., and Huang, H.-C.: Suomi-NPP VIIRS aerosol algorithms and data products, J. Geophys. Res.-Atmos., 118, 12673 12689, doi:10.1002/2013JD020449, 2013.

Kanamitsu, M.: Description of the NMC Global Data Assimilation and Forecast System, Weather Forecast., 4, 335-342, doi:10.1175/1520-0434(1989)004<0335:DOTNGD>2.0.CO;2, 1989.

Kaufman, Y. J., Tanré, D., Remer, L. A., Vermote, E. F., Chu, A., and Holben, B. N.: Operational remote sensing of tropospheric aerosol over land from EOS moderate resolution imaging spectroradiometer, J. Geophys. Res., 102, 17051-17068, doi:10.1029/96JD03988, 1997a.

Kaufman, Y. J., Wald, A. E., Remer, L. A., Gao, B.-C., Li, R.-R., and Flynn, L.: The MODIS 2.1- $\mu$ m channel-correlation with visible reflectance for use in remote sensing of aerosol, IEEE T. Geosci. Remote, 35, 1286-1298, doi:10.1109/36.628795, $1997 \mathrm{~b}$.

King, M. D., Menzel, W. P., Kaufman, Y. J., Tanré, D., Gao, B.C., Platnick, S., Ackerman, S. A., Remer, L. A., Pincus, R., and Hubanks, P. A.: Cloud and aerosol properties, pre- 
cipitable water, and profiles of temperature and water vapor from MODIS, IEEE T. Geosci. Remote, 41, 442-458, doi:10.1109/TGRS.2002.808226, 2003.

Koepke, P.: Effective reflectance of oceanic whitecaps, Appl. Optics, 23, 1816-1824, doi:10.1364/AO.23.001816, 1984.

Kondragunta, S., Lee, P., McQueen, J., Kittaka, C., Prados, A. I., Ciren, P., Laszlo, I., Pierce, R. B., Hoff, R., and Szykman, J. J.: Air quality forecast verification using satellite data, J. Appl. Meteorol. Clim., 47, 425-442, doi:10.1175/2007JAMC1392.1, 2008.

Kopp, T. J., Thomas, W., Heidinger, A. K., Botambekov, D., Frey, R. A., Hutchison, K. D., Iisager, B. D., Brueske, K., and Reed, B.: The VIIRS Cloud Mask: progress in the first year of S-NPP toward a common cloud detection scheme, J. Geophys. Res.-Atmos., 119, 2441-2456, doi:10.1002/2013JD020458, 2014.

Koren, I., Feingold, G., and Remer, L. A.: The invigoration of deep convective clouds over the Atlantic: aerosol effect, meteorology or retrieval artifact?, Atmos. Chem. Phys., 10, 8855-8872, doi:10.5194/acp-10-8855-2010, 2010.

Levy, R. C., Remer, L. A., Martins, J. V., Kaufman, Y. J., PlanaFattori, A., Redemann, J., and Wenny, B.: Evaluation of the MODIS aerosol retrievals over ocean and land during CLAMS, J. Atmos. Sci., 62, 974-992, doi:10.1175/JAS3391.1, 2005.

Levy, R. C., Remer, L. A., and Dubovik, O.: Global aerosol optical properties and application to Moderate Resolution Imaging Spectroradiometer aerosol retrieval over land, J. Geophys. Res.Atmos., 112, D13210, doi:10.1029/2006JD007815, 2007a.

Levy, R. C., Remer, L. A., Mattoo, S., Vermote, E. F., and Kaufman, Y. J.: Second-generation operational algorithm: retrieval of aerosol properties over land from inversion of Moderate Resolution Imaging Spectroradiometer spectral reflectance, J. Geophys. Res.-Atmos., 112, D13211, doi:10.1029/2006JD007811, $2007 \mathrm{~b}$.

Levy, R. C., Leptoukh, G. G., Kahn, R., Zubko, V., Gopalan, A., and Remer, L. A.: A critical look at deriving monthly aerosol optical depth from satellite data, IEEE T. Geosci. Remote, 47, 2942-2956, doi:10.1109/TGRS.2009.2013842, 2009.

Levy, R. C., Remer, L. A., Kleidman, R. G., Mattoo, S., Ichoku, C., Kahn, R., and Eck, T. F.: Global evaluation of the Collection 5 MODIS dark-target aerosol products over land, Atmos. Chem. Phys., 10, 10399-10420, doi:10.5194/acp-10-10399-2010, 2010.

Levy, R. C., Mattoo, S., Munchak, L. A., Remer, L. A., Sayer, A. M., Patadia, F., and Hsu, N. C.: The Collection 6 MODIS aerosol products over land and ocean, Atmos. Meas. Tech., 6, 2989-3034, doi:10.5194/amt-6-2989-2013, 2013.

Li, R. R., Kaufman, Y. J., Gao, B. C., and Davis, C. O.: Remote sensing of suspended sediments and shallow coastal waters, IEEE T. Geosci. Remote, 41, 559-566, 2003.

Li, Z., Zhao, X., Kahn, R., Mishchenko, M., Remer, L., Lee, K.-H., Wang, M., Laszlo, I., Nakajima, T., and Maring, H.: Uncertainties in satellite remote sensing of aerosols and impact on monitoring its long-term trend: a review and perspective, Ann. Geophys., 27, 2755-2770, doi:10.5194/angeo-27-2755-2009, 2009.

Lin, J., Pan, D., Davis, S. J., Zhang, Q., He, K., Wang, C., Streets, D. G., Wuebbles, D. J., and Guan, D.: China's international trade and air pollution in the United States, P. Natl. Acad. Sci. USA, 111, 1736-1741, doi:10.1073/pnas.1312860111, 2014.
Liu, H., Remer, L. A., Huang, J., Huang, H.-C., Kondragunta, S., Laszlo, I., Oo, M., and Jackson, J. M.: Preliminary evaluation of S-NPP VIIRS aerosol optical thickness, J. Geophys. Res.Atmos., 119, 3942-3962, doi:10.1002/2013JD020360, 2014.

Liu, L. and Mishchenko, M. I.: Toward unified satellite climatology of aerosol properties: direct comparisons of advanced level 2 aerosol products, J. Quant. Spectrosc. Ra., 109, 2376-2385, doi:10.1016/j.jqsrt.2008.05.003, 2008.

Loeb, N. G. and Manalo-Smith, N.: Top-of-atmosphere direct radiative effect of aerosols over global oceans from merged CERES and MODIS observations, J. Climate, 18, 3506-3526, doi:10.1175/JCLI3504.1, 2005.

Loeb, N. G., Sun, W., Miller, W. F., Loukachine, K., and Davies, R.: Fusion of CERES, MISR, and MODIS measurements for top-ofatmosphere radiative flux validation, J. Geophys. Res.-Atmos., 111, 18209, doi:10.1029/2006JD007146, 2006.

Lyapustin, A., Wang, Y., Laszlo, I., Kahn, R., Korkin, S., Remer, L., Levy, R., and Reid, J. S.: Multiangle implementation of atmospheric correction (MAIAC): 2. Aerosol algorithm, J. Geophys. Res.-Atmos., 116, D03211, doi:10.1029/2010JD014986, 2011.

Lyapustin, A., Wang, Y., Xiong, X., Meister, G., Platnick, S., Levy, R., Franz, B., Korkin, S., Hilker, T., Tucker, J., Hall, F., Sellers, P., Wu, A., and Angal, A.: Scientific impact of MODIS C5 calibration degradation and C6+ improvements, Atmos. Meas. Tech., 7, 4353-4365, doi:10.5194/amt-7-4353-2014, 2014.

Martins, J. V., Tanré, D., Remer, L., Kaufman, Y., Mattoo, S., and Levy, R.: MODIS Cloud screening for remote sensing of aerosols over oceans using spatial variability, Geophys. Res. Lett., 29, 8009, doi:10.1029/2001GL013252, 2002.

Mishchenko, M. I. and Geogdzhayev, I. V.: Satellite remote sensing reveals regional tropospheric aerosol trends, Opt. Express, 15, 7423-7438, doi:10.1364/OE.15.007423, 2007.

Mishchenko, M. I., Geogdzhayev, I. V., Cairns, B., Carlson, B. E., Chowdhary, J., Lacis, A. A., Liu, L., Rossow, W. B., and Travis, L. D.: Past, present, and future of global aerosol climatologies derived from satellite observations: a perspective, J. Quant. Spectrosc. Ra., 106, 325-347, doi:10.1016/j.jqsrt.2007.01.007, 2007a.

Mishchenko, M. I., Geogdzhayev, I. V., Rossow, W. B., Cairns, B., Carlson, B. E., Lacis, A. A., Liu, L., and Travis, L. D.: Long-term satellite record reveals likely recent aerosol trend, Science, 315, 1543-1543, doi:10.1126/science.1136709, 2007b.

Mishchenko, M. I., Liu, L., Geogdzhayev, I. V., Li, J., Carlson, B. E., Lacis, A. A., Cairns, B., and Travis, L. D.: Aerosol retrievals from channel-1 and -2 AVHRR radiances: long-term trends updated and revisited, J. Quant. Spectrosc. Ra., 113, 1974-1980, doi:10.1016/j.jqsrt.2012.05.006, 2012.

National Research Council (US), Committee on Climate Data Records from NOAA Operational Satellites: Climate Data Records from Environmental Satellites, National Academy Press, Washington, D.C., USA, 2004.

Remer, L. A., Kaufman, Y. J., Tanré, D., Mattoo, S., Chu, D. A., Martins, J. V., Li, R. R., Ichoku, C., Levy, R. C., Kleidman, R. G., Eck, T. F., Vermote, E., and Holben, B. N.: The MODIS aerosol algorithm, products, and validation, J. Atmos. Sci., 62, 947-973, doi:10.1175/JAS3385.1, 2005.

Remer, L., Kaufman, Y., and Kleidman, R.: Comparison of three years of terra and aqua MODIS aerosol optical thickness 
over the global oceans, IEEE Geosci. Remote S., 3, 537-540, doi:10.1109/LGRS.2006.879562, 2006.

Remer, L. A., Kleidman, R. G., Levy, R. C., Kaufman, Y. J., Tanré, D., Mattoo, S., Martins, J. V., Ichoku, C., Koren, I., Yu, H., and Holben, B. N.: Welcome | AGU, J. Geophys. Res.-Atmos., 113, D14S07, doi:10.1029/2007JD009661, 2008.

Remer, L. A., Mattoo, S., Levy, R. C., Heidinger, A., Pierce, R. B., and Chin, M.: Retrieving aerosol in a cloudy environment: aerosol product availability as a function of spatial resolution, Atmos. Meas. Tech., 5, 1823-1840, doi:10.5194/amt-5-1823-2012, 2012.

Salomonson, V. V., Barnes, W. L., Maymon, P. W., Montgomery, H. E., and Ostrow, H.: MODIS: advanced facility instrument for studies of the Earth as a system, IEEE T. Geosci. Remote, 27, 145-153, 1989.

Shi, Y., Zhang, J., Reid, J. S., Holben, B., Hyer, E. J., and Curtis, C.: An analysis of the collection 5 MODIS over-ocean aerosol optical depth product for its implication in aerosol assimilation, Atmos. Chem. Phys., 11, 557-565, doi:10.5194/acp-11-557-2011, 2011

Smirnov, A., Holben, B. N., Slutsker, I., Giles, D. M., McClain, C. R., Eck, T. F., Sakerin, S. M., Macke, A., Croot, P., Zibordi, G., Quinn, P. K., Sciare, J., Kinne, S., Harvey, M., Smyth, T. J., Piketh, S., Zielinski, T., Proshutinsky, A., Goes, J. I., Nelson, N. B., Larouche, P., Radionov, V. F., Goloub, P., Krishna Moorthy, K., Matarrese, R., Robertson, E. J., and Jourdin, F.: Maritime Aerosol Network as a component of Aerosol Robotic Network, J. Geophys. Res., 114, 06204, doi:10.1029/2008JD011257, 2009.

Tanré, D., Herman, M., and Kaufman, Y. J.: Information on aerosol size distribution contained in solar reflected spectral radiances, J. Geophys. Res.-Atmos., 101, 19043-19060, doi:10.1029/96JD00333, 1996.

Tanré, D., Kaufman, Y. J., Herman, M., and Mattoo, S.: Remote sensing of aerosol properties over oceans using the MODIS/EOS spectral radiances, J. Geophys. Res., 102, 1697116988, doi:10.1029/96JD03437, 1997.

Torres, O., Bhartia, P. K., Herman, J. R., Sinyuk, A., Ginoux, P., and Holben, B.: A Long-Term Record of Aerosol Optical Depth from TOMS Observations and Comparison to AERONET Measurements, J. Atmos. Sci., 59, 398-413, doi:10.1175/15200469(2002)059<0398:ALTROA>2.0.CO;2, 2002.

Turpie, K. R., Robinson, W. D., Franz, B. A., Eplee, R. E., Meister, G., Fireman, G. F., Patt, F. S., Barnes, R. A., and McClain, C. R.: Suomi NPP VIIRS ocean color data product early mission assessment, in: Proc. SPIE, 8510, Earth Observing Systems XVII, San Diego, CA, USA, 15 October 2012, 85101H, doi:10.1117/12.931113, 2012.

Turpie, K. R., Eplee, R. E., Franz, B. A., and Del Castillo, C.: Calibration uncertainty in ocean color satellite sensors and trends in long-term environmental records, in: Proc. SPIE, 9111, Ocean Sensing and Monitoring VI, Baltimore, MD, USA, 6-7 May 2014, 911103, doi:10.1117/12.2053427, 2014
Uprety, S., Cao, C., Xiong, X., Blonski, S., Wu, A., and Shao, X.: Radiometric intercomparison between Suomi-NPPVIIRS and AquaMODIS reflective solar bands using simultaneous nadir overpass in the low latitudes, J. Atmos. Ocean. Tech., 30, 2720 2736, doi:10.1175/JTECH-D-13-00071.1, 2013.

van Donkelaar, A., Martin, R. V., Brauer, M., Kahn, R., Levy, R., Verduzco, C., and Villeneuve, P. J.: Global estimates of ambient fine particulate matter concentrations from satellite-based aerosol optical depth: development and application, Environ. Health Persp., 118, 847-855, doi:10.1289/ehp.0901623, 2010.

Vermote, E. F. and Kotchenova, S.: Atmospheric correction for the monitoring of land surfaces, J. Geophys. Res., 113, D23S90, doi:10.1029/2007JD009662, 2008.

Vermote, E. F., Saleous, El, N., Justice, C. O., Kaufman, Y. J., Privette, J. L., Remer, L., Roger, J. C., and Tanré, D.: Atmospheric correction of visible to middle-infrared EOS-MODIS data over land surfaces: background, operational algorithm and validation, J. Geophys. Res., 102, 17131-17141, doi:10.1029/97JD00201, 1997.

Vermote, E. F., Saleous, El, N. Z., and Justice, C. O.: Atmospheric correction of MODIS data in the visible to middle infrared: first results, Remote Sens. Environ., 83, 97-111, doi:10.1016/S00344257(02)00089-5, 2002.

Vermote, E., Justice, C., and Csiszar, I.: Early evaluation of the VIIRS calibration, cloud mask and surface reflectance Earth data records, Remote Sens. Environ., 148, 134-145, doi:10.1016/j.rse.2014.03.028, 2014.

Weatherhead, E. C., Reinsel, G. C., Tiao, G. C., Meng, X.-L., Choi, D., Cheang, W.-K., Keller, T., DeLuisi, J., Wuebbles, D. J., Kerr, J. B., Miller, A. J., Oltmans, S. J., and Frederick, J. E.: Factors affecting the detection of trends: statistical considerations and applications to environmental data, J. Geophys. Res., 103, 17149, doi:10.1029/98JD00995, 1998.

Wiscombe, W. J.: Improved Mie scattering algorithms, Appl. Optics, 19, 1505-1509, doi:10.1364/AO.19.001505, 1980.

Xiong, X., Chiang, K., Sun, J., Barnes, W. L., Guenther, B., and Salomonson, V. V.: NASA EOS Terra and Aqua MODIS on-orbit performance, Adv. Space Res., 43, 413-422, doi:10.1016/j.asr.2008.04.008, 2009.

Zhang, J. and Reid, J. S.: A decadal regional and global trend analysis of the aerosol optical depth using a data-assimilation grade over-water MODIS and Level 2 MISR aerosol products, Atmos. Chem. Phys., 10, 10949-10963, doi:10.5194/acp-1010949-2010, 2010.

Zhao, T. X.-P., Laszlo, I., Guo, W., Heidinger, A., Cao, C., Jelenak, A., Tarpley, D., and Sullivan, J.: Study of long-term trend in aerosol optical thickness observed from operational AVHRR satellite instrument, J. Geophys. Res.-Atmos., 113, D07201, doi:10.1029/2007JD009061, 2008. 